Federal Reserve Bank of Dallas

Globalization and Monetary Policy Institute

Working Paper No. 43

http://www.dallasfed.org/assets/documents/institute/wpapers/2010/0043.pdf

\title{
Transitional Dynamics of Output and Factor Income Shares: Lessons from East Germany*
}

\author{
Simona E. Cociuba \\ Federal Reserve Bank of Dallas
}

January 2010

\begin{abstract}
I evaluate the quantitative implications of technology change and government policies for output and factor income shares during East Germany's transition since 1990. I model an economy that gains access to a high productivity technology embodied in new plants. As existing low productivity plants decrease production, the capital income share varies due to variation in the profit share of these plants. Two policies - transfers and governmentmandated wage increases - have opposite effects on output growth, but both contribute to reducing the capital share during the transition. The model's output and capital share line up with counterparts in East German data.
\end{abstract}

JEL codes: E20, E25, O11

\footnotetext{
* Simona E. Cociuba, Research Department, Federal Reserve Bank of Dallas, 2200 N. Pearl Street, Dallas, TX 75201. Simona.Cociuba@dal.frb.org. I thank Michele Boldrin, Ellen McGrattan, and Edward Prescott for invaluable advice. I also thank Laurence Ales, V.V. Chari, Jonathan Eaton, Larry Jones, Karen Lewis, Lynn MacDonald, Ananth Ramanarayanan, James Schmitz, Alice Schoonbroodt and Alexander Ueberfeldt for many helpful comments and suggestions. The views in this paper are those of the author and do not necessarily reflect the views of the Federal Reserve Bank of Dallas or the Federal Reserve System.
} 


\section{Introduction}

Of the many economies that underwent economic restructuring since the early 1990s, East Germany stands out due to various policies implemented by the government. Two striking policies are the large transfers received from West Germany and the dramatic increases in wages agreed upon by unions and the government. I examine the implications of these policies on the economic development of East Germany, in a model with embodied technological change. I find that transfers and high wages had a significant impact on East Germany's output growth and factor income shares.

The monetary transfers East Germany has received from West Germany since 1990 are very large, ranging from 30 to 50 percent of East Germany's gross domestic product each year. In spite of this extensive support, East Germany did not experience the growth miracle many had hoped for. ${ }^{1}$ Equally puzzling is the behavior of East Germany's capital income share. In 1991, the share of income attributed to capital was very low at 14 percent, and it rose throughout the transition to the more standard figure of 34 percent. I build a model that can account for the observed dynamics of output and factor income shares in East Germany. In the model, transfers have a positive impact on growth, to the extent that they are used to promote capital investment. ${ }^{2}$ Moreover, dramatic increases in wages, like those observed in East Germany, depress output growth by deterring capital accumulation (as suggested, for example, in Akerlof, Rose, Yellen, and Hessenius (1991) and Sinn (2007)) and by depressing labor supply. The two policies have somewhat offsetting effects on output growth, which helps explain why a growth miracle did not occur in East Germany. When coupled with technology change, transfers and high wage increases contribute to lowering the returns to capital, helping to account for the behavior of the capital income share.

I develop a dynamic general equilibrium model in which an economy gains access to a higher productivity technology embodied in new plants. This is motivated by the fact that, following the reforms in the early 1990s, East Germany and other Eastern European economies integrated into the world economy and started to benefit from the technologies of industrialized economies. In the model, production takes place at individual plants that may be operated or left idle at any given time. These plants are the capital stock of the economy, so I shall use the terms "plants" and "capital" interchangeably henceforth. As

\footnotetext{
${ }^{1}$ Hoffmann (1992) documents the differing outlooks on the development of East Germany that prevailed early in the transition. Some believed that East Germany would grow fast, while others feared it would develop into a depressed region. Between 1991 and 2006, the average annual growth rate of gross domestic product per working-age person in East Germany was 4.5 percent. In contrast, Poland, an economy that did not benefit from large transfers from the rest of the world, grew by 4 percent on average. By comparison, East Germany's performance is less than stellar.

${ }^{2}$ Fischer, Sahay, and Végh (1996) also show that foreign aid is conducive to higher GDP growth.
} 
high productivity plants are built gradually over time, the existing low productivity plants decrease their production and eventually shut down.

The two policies are incorporated in the model as follows. Transfers from the rest of the world can be used either for consumption or investment in capital, allowing the economy's total use of resources to expand beyond domestic production. Wage increases are modeled as union markups, the magnitude of which can be mandated by the government. ${ }^{3}$ During the transition from a low to a high productivity technology, transfers allow for more investment in the high productivity capital and thus have a positive effect on output growth. High wages depress the accumulation of capital and lower growth. Moreover, both policies lower the economy's labor supply which also contributes to reducing output growth.

The model's capital income share varies endogenously over time due to variation in the profit share of low productivity plants. The key feature of the model driving this result is a non-convexity in the plant-level production technology: plants require a minimum amount of labor to produce output, as in Hansen and Prescott (2005). If plants employ more than the minimum required labor, their profits are a constant share of output. However, if plants operate at the minimum scale, they hire more labor than would be the case in the absence of this labor constraint, and their profit share is low. During the transition, low productivity plants have a declining profit share of output and are gradually replaced with high productivity plants whose profit share is constant. As a result, the economy's capital income share displays U-shaped dynamics. Once all low productivity capital is left idle, the capital share is constant. In addition to the effects arising from technology change, the government policies contribute to lowering the capital share during the transition. Both transfers and government-mandated wage increases reduce the profit share of low productivity plants further, because they increase the cost of labor. ${ }^{4}$

I calibrate the model and examine its quantitative predictions. The model matches East Germany's output growth from 1991 to 2006. It also delivers a decline in output in the first years of the transition - albeit of a smaller than observed magnitude - due to a large decline in labor supply. This reduction in labor is consistent with data. Moreover, the model predicts the capital income share is low in 1991 and rises throughout the transition, as observed in

\footnotetext{
${ }^{3}$ Burda and Hunt (2001) argue that unions were able to choose wages in East Germany early in the transition. Akerlof, Rose, Yellen, and Hessenius (1991) argue that the West German government supported the wage increases since it thought this would prevent migration to the West and the ensuing reduction in Western wages. Sinn (2007) documents that the head of the Treuhandanstalt - the Trust set up to privatize the East German companies - was told, by the federal government, to stay away from the wage bargaining. He argues that the German government bears responsibility for allowing the wage increases.

${ }^{4}$ Sinn (2007, pp. 162-163) argues that the dramatic increase in wages in East Germany altered investment prospects and kept investors away. He documents that only 9 percent of the privatized East German companies were sold to foreign investors, and attributes this dearth of investors to expectations of reduced profits due to high wages.
} 
East German data. Technology change by itself generates relatively small variations in the capital share. The transfers and wage increases are important contributors to the capital share's initial decline, as they increase the cost of labor and lower profits of low productivity plants. The model also matches East German data on expenditure shares of output. It predicts high consumption to output and investment to output ratios due to the transfers available. Lastly, I perform a counterfactual experiment which shows that without the large government-mandated wage increases, East Germany would have grown more, partly due to faster accumulation of the higher productivity capital, and partly due to higher labor supply throughout the transition.

I also consider the model's predictions for Poland and contrast them with the results obtained for East Germany. During its transition, Poland received small transfers from the rest of the world, amounting to about 1.5 percent of gross domestic product, as compared to East Germany's 30 to 50 percent. In addition, Poland experienced more moderate wage growth as a result of the introduction of a special tax to discourage wage increases. The model predicts that the variation in the capital share during Poland's transition is moderate, as observed in the data. The capital income share varies over time due to technology change, while the contributions from the two policies are unimportant. The prediction for output misses the initial drop observed in Poland. While the model delivers an initial decline in output for East Germany due to a decline in labor supply, for Poland the reduction in labor is smaller and is offset entirely by the increase in capital accumulation.

A number of papers have explored factors common across transition economies that could account for the sharp declines in output observed in the early 1990s. ${ }^{5}$ It has been shown that some quantitatively important factors are: costs associated with the adoption of new technologies of production (as in Atkeson and Kehoe (1993)) or collapses in trade (Rodrik (1994) and Gorodnichenko, Mendoza, and Tesar (2009)). While this paper does not propose a theory of the sharp declines in output observed in all transition economies, it contributes to this literature by showing that part of the initial decline in output observed in East Germany was due to government policies that led to a large fall in labor supply. It is well documented that East Germany experienced the largest downturn in output in the first two years of transition among Eastern European economies. ${ }^{6}$ Moreover, the decline in labor supply was

\footnotetext{
${ }^{5}$ Declines in output for a number of transition economies are documented, for example, in Blanchard and Kremer (1997) and Roland and Verdier (1999). For a survey of the literature on the various explanation for these initial output declines, see Campos and Coricelli (2002).

${ }^{6}$ Dornbusch and Wolf (1994, Table 5.3) compare changes in gross domestic product for East Germany, Hungary, Czechoslovakia and Poland between 1989 and 1991 to emphasize the severity of East Germany's initial downturn. Also see Sinn and Sinn (1992, pp. 29-31). I reach the same conclusion when comparing gross domestic product per working-age person across a number of Eastern European economies.
} 
also large in East Germany compared to other economies. ${ }^{7}$ The quantitative analysis in this paper shows that the transfer and high wage policies contribute to reducing labor supply consistent with East German data. This leads to a sizable decline in the model's output early in the transition - a prediction that doesn't occur if transfers are small and wage growth is moderate.

This work also contributes to the literature on the variation in factor income shares. A number of existing papers document the cyclical properties of the labor income share in the U.S. and put forth theories that can account for these facts. It has been shown that a counter-cyclical labor share may arise due to an optimal risk-sharing arrangement between firms and workers (as in Boldrin and Horvath (1995) and Gomme and Greenwood (1995)), due to monopolistic competition and increasing returns to scale (Hornstein (1993)) or due to a capacity constraint that binds during periods of expansion (Hansen and Prescott (2005)). Moreover, Ríos-Rull and Santaeulàlia-Llopis (2009) emphasize the importance of understanding the effects of productivity shocks on the labor share, while Choi and Ríos-Rull (2008) explore the ability of a model with noncompetitive factor markets to generate such effects. This paper shares with this work the interest in understanding variations in factor income shares, but it differs in that the focus is on low frequency changes in factor shares. I show that variations in factor shares arise during the process of technology adoption. While this paper analyses the experience of East Germany, this finding has potential for a wider applicability. Technology change induces relatively small variations in the model's capital share, and so it is a possible mechanism that could account for some of the changes in factor shares over time in the U.S. and other economies.

The remainder of the paper is organized as follows. Section 2 presents facts pertaining to the transition of East Germany and compares its experience with that of Poland. Section 3 develops the theoretical framework. Section 4 discusses the predictions of the model for output growth and factor income shares, highlighting in turn the contributions of technology and government policies. Section 5 presents the quantitative results, and Section 6 concludes.

\section{On the Transitions in East Germany and Poland}

This section presents data on output, the capital income share, net transfers received from the rest of the world and wages for East Germany and Poland. The sources of data are given in Appendix A.1.

\footnotetext{
${ }^{7}$ Blanchard, Commander, and Coricelli (1995) document changes in employment for a number of economies, while Dornbusch and Wolf (1994) report it for East Germany. I compute hours worked per working-age person for East Germany (see footnote 22) and a number of other transition economies (see Appendix A.1 for data sources). I find the decline in hours was largest in East Germany.
} 
Output per working-age person (i.e. population 15-64) in both East Germany and Poland contracted for a period of two years, but displayed positive growth thereafter (see Figure 1). Between 1989 and 1991, East German gross domestic product per working-age person shrunk by about one third. Thereafter, the economy started to grow, initially very rapidly and then at a slower pace starting 1996. In comparison, the changes in GDP per working-age person in Poland were more moderate. The initial decline was smaller, at about 17 percent, while the growth in the early years of the transition was also lower compared to that of East Germany. However, the overall growth experience of the two economies has been relatively similar. Over the 16 year period from 1991 to 2006, output per working-age person grew on average by 4.5 percent in East Germany and by 4 percent in Poland.

The share of income accruing to capital shows interesting differences between the two economies. Following Kravis (1959) and Gollin (2002), I compute the capital income share, $\zeta$, as follows:

$$
\zeta=1-\frac{\text { Compensation of Employees }+ \text { Labor Income of Self-Employed }}{\text { Gross Domestic Product - Indirect Taxes }}
$$

Over the period 1991 to 2006, the capital share varied little in Poland, averaging 37 percent (see Figure 2). ${ }^{8}$ In contrast, the capital share varied greatly in East Germany. It was very low in 1991, at 14 percent, and then it increased over time, averaging 34 percent in the last ten years. ${ }^{9}$ Prior to 1991 , data needed to compute the capital share for both economies is incomplete. However, available estimates suggest that the capital share in East Germany in 1989 was much higher than the value observed in $1991 .^{10}$ The variation in the capital share in East Germany represents a large deviation from the relative constancy of this share documented by many authors. For example, Kaldor (1961) identifies the relative stability of the factor shares across time as a "stylized fact" of economic growth. Gollin (2002) documents the relative constancy of factor income shares across countries.

\footnotetext{
${ }^{8}$ After Poland joined the European Union in 2004, the compensation of employees to GDP ratio declined by about 4.5 percentage points. As a result, the capital income share increased to about 44 percent, as seen in the last few years in Figure 2. The lastest available data shows that the compensation to GDP ratio rose in 2008 relative to its level in $2004-2006$, suggesting that the capital share is now closer to 40 percent.

${ }^{9}$ The dramatic increase in the capital share in East Germany is driven by the decrease in the compensation of employees to GDP ratio. Between 1991 and 2006, this ratio declined by about 40 percent. Taking into account the labor income of self-employed and indirect taxes (as in equation 1) has a relatively small impact on the overall increase in the capital share over the 16 year period. For more detail, see Appendix A.1.

${ }^{10}$ One proxy for the level of the capital share is the compensation of employees to GDP ratio. As reported by Sinn and Sinn (1992, pp. 209-216), this ratio was about 40 percent in East Germany in 1989. (Similarly, in Poland this ratio was about 41 percent in the early 1990s.) Furthermore, East Germany's consumption of fixed capital, one component of capital income, was 15 percent of GDP in 1988, as reported by United Nations (1988, Table 1.3, p. 611). This value is close to the average depreciation to GDP ratio for East Germany during the 1980s. These facts suggest that the capital share was high in East Germany in 1989.
} 
Through the course of the transition, both economies benefited from transfers from the rest of the world. ${ }^{11}$ East Germany has received transfers from West Germany and the European Union. In 1991, net transfers were 52 percent of East German GDP. Although there has been a significant decline over time, net transfers to East Germany still amounted to 30 percent of GDP in 2002 (see left panel in Figure 6). A large portion of transfers has been channeled through social benefit programs to households and used for consumption purposes (see, for example, Jensen (2004)). Some transfers have been used to encourage investment by providing subsidies to firms. By contrast, Poland received transfers from the European Union averaging about 1.5 percent of GDP per year.

Another important difference between East Germany and Poland is in the wage policy adopted during the transition. Over the period 1989 to 1991, real hourly wages increased dramatically in East Germany compared to Poland (see Table 1). These high wages were made possible through the intervention of the powerful West German unions who had the government's support. One of the reasons for raising wages was the fear that East Germany would become an attractive location for foreign investors, due to low wage costs, and would provide unwanted competition for firms in West Germany (see, for example, Sinn (2007) and Burda and Funke (2001)). ${ }^{12}$ In contrast to East Germany's high wage policy, Poland's government introduced a temporary wage tax to discourage large increases in wages. Although many enterprises chose to raise wages and pay this punitive tax, wage growth in Poland was more moderate during the transition. ${ }^{13}$

In the next sections, I examine the facts presented here on output and the capital share through the lens of a model economy that receives transfers from the rest of the world and has government-mandated wage increases.

\footnotetext{
${ }^{11}$ Transfers are transactions in which an entity receives goods, services or cash payments from another entity without providing anything in return. Net transfers for East Germany and Poland are the difference between transfers received from the rest of the world and transfers paid to the rest of the world.

${ }^{12}$ Other reasons for the wage increases are discussed in Akerlof, Rose, Yellen, and Hessenius (1991). For details on the wage bargaining process and the rapid increase in wages in East Germany also see Krueger and Pischke (1995), Burda and Hunt (2001), Burda and Funke (2001), Dornbusch and Wolf (1994) and Sinn (2007, pp. 161-163). The last two sources also discuss the replacement of the East German mark with the deutschmark. They argue that the one-to-one currency conversion was not the main mistake made by the German government, but the wage increases that came after this conversion were more problematic. Particularly, without the ensuing wage increases, the currency conversion would have left East German wages at a relatively low level.

${ }^{13}$ For a discussion of the temporary wage controls instituted in Poland through the so-called popiwek tax, see, for example, Sachs (1993) and Freeman (1994).
} 


\section{Model Economy}

\subsection{Production Technology}

Aggregate output is produced from two factors of production: labor and capital. The aggregate labor input is a composite of differentiated types of labor. The capital input consists of plants where production can take place.

There are two types of plants distinguished by their productivity level $z_{i} \in\left\{z_{L}, z_{H}\right\}$, with $z_{L}<z_{H}$. I refer to plants with productivity level $z_{i}$ as $z_{i}$-plants. The output of a $z_{i}$-plant at time $t, y_{i, t}$, is modelled in the spirit of Hansen and Prescott (2005) and is given by:

$$
y_{i, t}= \begin{cases}z_{i} n_{i, t}^{1-\theta} & \text { if } n_{i, t} \geq \bar{n} \\ 0 & \text { otherwise }\end{cases}
$$

where $n_{i, t}$ is the quantity of composite labor input employed by a $z_{i}$-plant at time $t .^{14}$ There is a minimum requirement of (composite) labor necessary to operate a plant. This minimum is identical across plant types and is given by $\bar{n}$.

I constrain $\theta \in(0,1)$. This assumption guarantees that it is optimal to operate many small plants rather than one large plant. Moreover, all operating plants of the same type will employ the same amount of labor. The requirement that $n_{i, t} \geq \bar{n}$ together with a limited number of potential workers implies an upper bound on the number of plants that can be operated. Labor can be moved across locations at no cost, hence it will only be allocated to plants with $n_{i, t} \geq \bar{n}$. As a result, at any point in time some plants may be left idle.

Let $M_{i, t}$ denote the stock of $z_{i}$-plants that can potentially be operated at time $t$ and let $N_{t}$ denote the aggregate labor to be employed at time $t .{ }^{15}$ The aggregate production function of this economy is defined by $(3)$, where $m_{i, t}$ is the mass of $z_{i}$-plants that are operated at

\footnotetext{
${ }^{14}$ The plant labor input, $n_{i, t}, i \in\{L, H\}$ is a composite of differentiated types of labor, $l_{i, t}(j), j \in[0,1]$. Here $l_{i, t}(j)$ denotes the labor of type $j$ hired by a plant of type $z_{i}$ at time $t$. The choice of $l_{i, t}(j)$ can be separated from the choice of the composite plant labor input $n_{i, t}$. For details see the derivation of the demand for labor of type $j$ (equation 7 ), as well as footnote 16 .

${ }^{15}$ In this economy, the plants represent the entire capital stock of the economy. Equipment is typically a small fraction of the total capital stock (about 15\% in both East and West Germany) and I consider it to be tied to the structures/plants.
} 
time $t$ and are allocated $n_{i, t}$ units of labor input.

$$
\begin{gathered}
F\left(N_{t}, M_{H, t}, M_{L, t}\right) \equiv \max _{\left\{m_{i, t}, n_{i, t}\right\}_{i \in\{H, L\}}} m_{H, t} z_{H} n_{H, t}^{1-\theta}+m_{L, t} z_{L} n_{L, t}^{1-\theta} \\
\text { s.t. } m_{H, t} n_{H, t}+m_{L, t} n_{L, t} \leq N_{t} \\
0 \leq m_{i, t} \leq M_{i, t} \text {, for all } i \\
n_{i, t} \geq \bar{n}, \text { for all } i
\end{gathered}
$$

For each time period $t$, this is a static maximization problem. Finding the maximum output that can be produced in a given period involves allocating the aggregate labor input, $N_{t}$, across the available plants in the economy. If there are enough high productivity plants to employ all the labor that needs to be hired, then it is optimal to leave all the low productivity plants idle. However, if there is a scarcity of $z_{H}$-plants, some or all of the $z_{L}$-plants are operated. In problem (3) it is clear that the market clearing condition for aggregate labor holds with equality. The other inequality constraints bind or not, indicating the mass of plants that operate and the amount of labor input assigned to each plant.

Proposition 1 Let $\alpha \equiv\left((1-\theta) z_{H} / z_{L}\right)^{1 / \theta}$ and $\rho \equiv\left(z_{H} / z_{L}\right)^{1 / \theta}$. The aggregate production function is the solution to the maximization problem in (3) and is given by:

$$
F\left(N_{t}, M_{H, t}, M_{L, t}\right)= \begin{cases}z_{L}\left(\rho M_{H, t}+M_{L, t}\right)^{\theta} N_{t}^{1-\theta} & \text { if } N_{t} \geq \eta_{1, t} \\ z_{H} M_{H, t}^{\theta}\left(N_{t}-M_{L, t} \bar{n}\right)^{1-\theta}+z_{L} \bar{n}^{1-\theta} M_{L, t} & \text { if } \eta_{2, t} \leq N_{t} \leq \eta_{1, t} \\ A M_{H, t}+z_{L} \bar{n}^{-\theta} N_{t} & \text { if } \eta_{3, t} \leq N_{t} \leq \eta_{2, t} \\ z_{H} M_{H, t}^{\theta} N_{t}^{1-\theta} & \text { if } \eta_{4, t} \leq N_{t} \leq \eta_{3, t} \\ z_{H} \bar{n}^{-\theta} N_{t} & \text { if } N_{t} \leq \eta_{4, t}\end{cases}
$$

where $\eta_{1} \equiv\left(\rho M_{H, t}+M_{L, t}\right) \bar{n}, \eta_{2} \equiv\left(G_{\alpha} M_{H, t}+M_{L, t}\right) \bar{n}, \eta_{3} \equiv G_{\alpha} M_{H, t} \bar{n}, \eta_{4} \equiv M_{H, t} \bar{n}$ and where $G_{\alpha} \equiv \max \{1, \alpha\}$ and $A=\left[z_{H}\left(G_{\alpha}\right)^{1-\theta}-z_{L} G_{\alpha}\right] \bar{n}^{1-\theta}$.

Proof. See Appendix A.3.

To understand the aggregate production function in equation (4) recall that the plant production function has decreasing returns to scale for input levels above $\bar{n}$ (see equation 2 ). As a result, plants have an optimal size. Given this optimal size, if the stock of high productivity plants is not high enough to employ all the labor, then some or all of the low productivity plants operate. In the first branch of the production function, when $N_{t} \geq\left(\rho M_{H, t}+M_{L, t}\right) \bar{n}$, all plants of both types operate and are allocated more than $\bar{n}$ units of labor. For lower values of $N_{t}$, a higher fraction of the total labor input can be employed in high productivity 
plants and, as a result, the low productivity plants decrease their scale. First, low productivity plants hire $\bar{n}$ workers (see the second branch of the production function). Later, some low productivity plants stop operating. In this case, low productivity plants are not a scarce input in production and they earn no rent (see the third branch of the production function). Finally, no low productivity plants operate. In this case, all the labor is hired at high productivity plants and the aggregate production function is Cobb-Douglas. If $N_{t}<M_{H, t} \bar{n}$, only some high productivity plants operate and the rest are idle. This situation does not occur in the equilibrium of this model as is explained later.

Remark 1 The aggregate production function, $F: \mathbb{R}^{3} \rightarrow \mathbb{R}$ is: $(i)$ continuous, (ii) homogenous of degree one, (iii) weakly increasing (iv) differentiable everywhere except at $N=\eta_{1}=M_{H} \bar{n}$, and $(v)$ weakly concave.

The aggregate labor input in this economy is a composite of differentiated types of labor. Let $l_{t}(j)$ denote the labor of type $j, j \in[0,1]$. Then,

$$
N_{t}=\left[\int l_{t}(j)^{\nu} d j\right]^{1 / \nu}
$$

where $1 /(1-\nu)$ is the elasticity of substitution between the differentiated types of labor.

There is a representative firm in the economy that operates the plants. The problem of the representative firm can be stated in two parts. First, given factor prices: $r_{H, t}, r_{L, t}$ and $w_{t}$, the firm chooses $N_{t}, M_{H, t}$, and $M_{L, t}$ to maximize profits:

$$
\begin{gathered}
\max _{Y_{t}, N_{t}, M_{H, t}, M_{L, t}} Y_{t}-w_{t} N_{t}-r_{H, t} M_{H, t}-r_{L, t} M_{L, t} \\
\text { s.t. } Y_{t}=F\left(N_{t}, M_{H, t}, M_{L, t}\right)
\end{gathered}
$$

Second, for any given amount of aggregate labor, $N_{t}$, the demand for each differentiated type of labor, $l_{t}(j)$, is the solution to:

$$
\begin{aligned}
w_{t} N_{t} & =\min _{\left\{l_{t}(j)\right\}, j \in[0,1]} \int w_{t}(j) l_{t}(j) d j \\
\text { s.t. } N_{t} & \geq\left[\int l_{t}(j)^{\nu} d j\right]^{1 / \nu}
\end{aligned}
$$

where $w_{t}(j)$ is the wage for labor of type $j$. I impose $\nu \leq 1$ so that the problem in (6) has a solution. The demand for labor of type $j$ is given by:

$$
l_{t}(j)=\left(\frac{w_{t}}{w_{t}(j)}\right)^{1 /(1-\nu)} N_{t}
$$


where the aggregate wage is $w_{t}=\left[\int w_{t}(j)^{\nu /(\nu-1)} d j\right]^{(\nu-1) / \nu} \cdot 16$

\subsection{Consumers}

There is a large number of infinitely lived consumers with a specific type of labor. The consumers are organized in a continuum of unions indexed by $j, j \in[0,1]$. Each union represents consumers with a specific type of labor. Unions are modeled in the spirit of Blanchard and Kiyotaki (1987). Unions set the wage for labor of type $j$ and face a downward sloping demand for labor given by (7).

The preferences of a representative consumer in the $j$ th union are given by:

$$
\sum_{t=0}^{\infty} \beta^{t} U\left[C_{t}(j), l_{t}(j)\right]
$$

The $j$ th union chooses consumption, $C(j)$, chooses non-negative investments in the high and low type capital, $X_{H}(j)$ and $X_{L}(j)$, rents capital stocks $M_{H}(j)$ and $M_{L}(j)$, and chooses the wage rate $w(j)$, to maximize (8) subject to the demand for labor given in $(7)$, the budget constraints in (9) and the laws of motion for capital in (10).

$$
\begin{aligned}
\left(1+\tau_{C, t}\right) C_{t}(j)+X_{H, t}(j)+X_{L, t}(j) \leq & \left(1-\tau_{N, t}\right) w_{t}(j) l_{t}(j) \\
+ & +\left(1-\tau_{M, t}\right)\left[r_{H, t} M_{H, t}(j)+r_{L, t} M_{L, t}(j)\right] \\
& +\tau_{M, t}\left[\delta_{H} M_{H, t}(j)+\delta_{L} M_{L, t}(j)\right]+T_{t} \\
& \\
M_{H, t+1}(j)= & \left(1-\delta_{H}\right) M_{H, t}(j)+X_{H, t}(j) \\
M_{L, t+1}(j)= & \left(1-\delta_{L}\right) M_{L, t}(j)+X_{L, t}(j)
\end{aligned}
$$

In the equations above, $r_{H, t}$ and $r_{L, t}$ are the rental rates of capital, $\tau_{C, t}, \tau_{N, t}, \tau_{M, t}$ are taxes on consumption, labor income and capital income, respectively, and $T_{t}$ are lump-sum transfers. The union takes the rental rates, the aggregate wage, $w_{t}$, and the tax rates as exogenously given.

\footnotetext{
${ }^{16}$ Similarly, given the composite labor input, $n_{i, t}$, hired at date $t$ by a $z_{i}$-plant, one can derive the demand for each differentiated type of plant labor input $l_{i, t}(j)$, where $i \in\{L, H\}$ and $j \in[0,1]$. The following holds: $l_{i, t}(j)=\left(w_{t} / w_{t}(j)\right)^{1 /(1-\nu)} n_{i, t}$. Thus, using equation $(7)$, I get $l_{i, t}(j)=\left(n_{i, t} / N_{t}\right) \cdot l_{t}(j)$, for all $i \in\{L, H\}$ for all $j \in[0,1]$.
} 


\subsection{Government}

The government taxes consumption, labor income and capital income. It permits depreciation allowances as given by $\tau_{M, t}\left(\delta_{H} M_{H, t}(j)+\delta_{L} M_{L, t}(j)\right)$ for every $j$. Transfers from the rest of the world are an additional source of government revenues and are denoted by $\overline{T r}_{t}$. The revenues collected by the government are lump-sum rebated to the households. Let this rebate be denoted by $T_{t}$. The government balances its budget every period, hence:

$$
\begin{aligned}
T_{t}= & \int\left[\tau_{C, t} C_{t}(j)+\tau_{N, t} w_{t}(j) l_{t}(j)\right] d j \\
& +\int\left[\tau_{M, t}\left(r_{H, t}-\delta_{H}\right) M_{H, t}(j)+\tau_{M, t}\left(r_{L, t}-\delta_{L}\right) M_{L, t}(j)\right] d j+\overline{T r}_{t}
\end{aligned}
$$

The government has an additional role in this model: to influence the monopoly power of the unions and the wage markups they can charge. This policy is modeled as a provision to make unions set wages perfectly competitively if the markups exceed $1 / \bar{\nu}_{t}$ where $\bar{\nu}_{t} \geq \nu$. Under such a policy it is clear that the markup charged by unions is $1 / \bar{\nu}_{t}$.

\subsection{Equilibrium}

In this section, I define and characterize an equilibrium.

Definition 1 An equilibrium are allocations $\left\{Y_{t}, N_{t}, M_{H, t}, M_{L, t},\left\{l_{t}^{d}(j)\right\}_{j \in[0,1]}\right\}_{t=0}^{\infty}$ and $\left\{\left\{C_{t}(j), l_{t}^{s}(j), X_{H, t}(j), X_{L, t}(j), M_{H, t}(j), M_{L, t}(j)\right\}_{j \in[0,1]}\right\}_{t=0}^{\infty}$ and prices $\left\{r_{H, t}, r_{L, t}, w_{t},\left\{w_{t}(j)\right\}_{j \in[0,1]}\right\}_{t=0}^{\infty}$ such that:

1. Taking as given parameters $\left\{\tau_{C, t}, \tau_{N, t}, \tau_{M, t}, \overline{T r}_{t}, \bar{\nu}_{t}\right\}_{t=0}^{\infty}$, initial conditions $M_{L, 0}, M_{H, 0}$ and prices $\left\{r_{H, t}, r_{L, t}, w_{t}\right\}_{t=0}^{\infty}$, the allocation $\left\{C_{t}(j), l_{t}^{s}(j), X_{H, t}(j), X_{L, t}(j), M_{H, t}(j)\right.$, $\left.M_{L, t}(j)\right\}_{t=0}^{\infty}$ and $\left\{w_{t}(j)\right\}_{t=0}^{\infty}$ solve the $j$ th union's problem for every $j \in[0,1]$.

2. Taking as given prices, $\left\{Y_{t}, N_{t}, M_{H, t}, M_{L, t},\left\{l_{t}^{d}(j)\right\}_{j \in[0,1]}\right\}_{t=0}^{\infty}$ solves the firm's problem.

3. The government balances its budget given by equation 11 for all $t$. 
4. The markets clear and the resource constraint holds for all $t$ :

$$
\begin{gathered}
l_{t}^{d}(j)=l_{t}^{s}(j)=l_{t}(j) \text { for all } j \\
\int M_{H, t}(j) d j=M_{H, t} \\
\int M_{L, t}(j) d j=M_{L, t} \\
\int\left[C_{t}(j)+X_{H, t}(j)+X_{L, t}(j)\right] d j \leq Y_{t}+\overline{T r}_{t}
\end{gathered}
$$

Consider an economy that transitions to a higher productivity technology. Initially, the economy has only $z_{L}$-plants. Due to the availability of more productive $z_{H}$-plants, there are no further investments made in the stock of low productivity plants. This follows from the fact that building plants of either type is equally costly, but the $z_{L}$-plants are less productive. ${ }^{17}$ As a result, the stock of $z_{L}$-plants depreciates over time at rate $\delta_{L} \geq 0$, while the more productive $z_{H}$-plants accumulate during the transition.

The first order conditions of the $j$ th union problem are summarized by $X_{L, t}(j)=0$, the budget constraints, the laws of motion for capital, as well as:

$$
\begin{aligned}
\frac{U_{C}\left(C_{t}(j), l_{t}(j)\right)}{U_{C}\left(C_{t+1}(j), l_{t+1}(j)\right)} & =\beta \frac{1+\tau_{C, t}}{1+\tau_{C, t+1}}\left(1+\left(1-\tau_{M, t+1}\right)\left(r_{H, t+1}-\delta_{H}\right)\right) \\
w_{t}(j) & =\operatorname{markup} \cdot \frac{\left(1+\tau_{C, t}\right)}{\left(1-\tau_{N, t}\right)} \frac{-U_{l}\left[C_{t}(j), l_{t}(j)\right]}{U_{C}\left[C_{t}(j), l_{t}(j)\right]} \\
\lim _{t \rightarrow \infty} \beta^{t} U_{C}\left[C_{t}(j), l_{t}(j)\right] M_{H, t+1}(j) & =0
\end{aligned}
$$

The markup in the intratemporal condition (12) is given by:

$$
\operatorname{markup}=\min \left\{\frac{1}{\nu}, \frac{1}{\bar{\nu}_{t}}\right\}
$$

where $1 / \nu$ is the wage markup that the union would choose, and $1 / \bar{\nu}_{t}$ is the markup allowed by the government. ${ }^{18}$

I assume that $\nu \leq \bar{\nu}_{t} \leq 1$ for all $t$. The wage markup in equilibrium is thus $1 / \bar{\nu}_{t}$, which means that the wage increases are mandated by the government. The markup is an exogenous policy in the model. The values chosen for $\bar{\nu}_{t}$ in numerical experiments are discussed in Section 5.1.

\footnotetext{
${ }^{17}$ Using the aggregate production function in (4), it is easy to show that the marginal product of high productivity plants, $M_{H, t}$, is strictly higher than the marginal product of low productivity plants, $M_{L, t}$, whenever all high productivity plants operate.

${ }^{18}$ See Appendix A.3 for a derivation of the intratemporal condition (12).
} 
The first order conditions of the representative firm's problem are:

$$
r_{i, t}=\frac{\partial F\left(N_{t}, M_{H, t}, M_{L, t}\right)}{\partial M_{i, t}}, i \in\{L, H\}, \quad w_{t}=\frac{\partial F\left(N_{t}, M_{H, t}, M_{L, t}\right)}{\partial N_{t}}
$$

Given the symmetry of the unions, they all make the same choices. In particular, $w_{t}(j)=$ $w_{t}$ and $l_{t}(j)=N_{t}$. Thus, from now on I drop the $j$ subscripts.

Proposition 2 Along the transition path, as the stock of low productivity plants approaches zero asymptotically, the aggregate production function in (4) becomes:

$$
\lim _{M_{L, t} \rightarrow 0} F\left(N_{t}, M_{H, t}, M_{L, t}\right)= \begin{cases}z_{H} M_{H, t}^{\theta} N_{t}^{1-\theta} & \text { if } N_{t} \geq M_{H, t} \bar{n} \\ z_{H} \bar{n}^{-\theta} N_{t} & \text { if } N_{t} \leq M_{H, t} \bar{n}\end{cases}
$$

Proof. See Appendix A.3.

Proposition 3 If $\bar{n} \leq\left[\frac{z_{H} \theta\left(1-\tau_{M}\right)}{\beta^{-1}-1+\left(1-\tau_{M}\right) \delta_{H}}\right]^{1 /(\theta-1)}$ then a unique steady state exists in which all $z_{H}$-plants operate and the aggregate production function is Cobb-Douglas.

Proof. Suppose there is a steady state in which some $z_{H}$-plants are idle, and that this steady state is reached at time $T$. It must be that it is not possible to allocate at least $\bar{n}$ units of labor to all $z_{H}$-plants, i.e. $N_{T}<M_{H, T} \bar{n}$. The output produced equals $z_{H} \bar{n}^{-\theta} N_{T}$ (see Proposition 2). Given that the $z_{H}$-plants are not a scarce input in production, they earn no rents. There will be no investments undertaken: $X_{H, T}=0$. Thus, the capital stock depreciates: $M_{H, T+1}<M_{H, T}$. This contradicts the fact that a steady state was reached at time $T$.

Hence, in a steady state all $z_{H}$-plants operate and $N^{*} \geq M_{H}^{*} \bar{n}$, where $*$ denotes steady state. Using the model's first order conditions, it is easy to show that this inequality is equivalent to the one specified in the text of the proposition.

The minimum labor requirement, $\bar{n}$, is a parameter of the model. In numerical experiments, I choose $\bar{n}$ such that the parameter restriction in Proposition (3) is satisfied. Along the transition path and in the new steady state, all $z_{H}$ plants operate. There is no uncertainty in the model and due to the trade-off between consumption and savings, it is not optimal to accumulate too many $z_{H}$-plants and then leave some idle.

\section{Predictions for Output and Factor Shares}

In this section, I describe the dynamics of the model. First, I analyze an economy that undergoes technology change, but receives no transfers from the rest of the world and has 
perfectly competitive wages. I focus on the model's predictions for output and the capital income share. Later, I discuss the model results in the presence of the government policies. Finally, I show that the policies affect the capital share in a nonlinear fashion.

\subsection{Technology Change}

Consider an economy as in Section 3, in which transfers are zero and the government mandates that wages be perfectly competitive, i.e. $\overline{T r}_{t}=0$ and $\bar{\nu}_{t}=1$ for all $t$.

The economy transitions from a low productivity technology, $z_{L}$, to a high productivity technology, $z_{H}$. Initially there are only $z_{L}$-plants in the economy. The better technology becomes available and consumers stop investing in the low productivity plants, which depreciate over time as discussed previously. As $z_{H}$-plants accumulate, a larger fraction of the total labor in the economy is hired at these plants. As a result, low productivity plants reduce their scale until they all hire only $\bar{n}$ labor. ${ }^{19}$ Next, one of two scenarios can occur. If the productivity difference between the two types of plants is large enough (i.e. $\alpha>1$ ), only a fraction of the low productivity plants continue to operate and hire $\bar{n}$ units of labor, while the rest are left idle. ${ }^{20}$ However, if the difference in plant level productivities is smaller (i.e. $\alpha<1$ ), all $z_{L}$-plants operate throughout the transition at the minimum scale and only exit the economy as they depreciate. The intuition is that when $\alpha>1$, the high productivity capital stock accumulates faster during the transition and the high productivity plants also hire more labor compared to the case when $\alpha<1$. Low productivity plants cannot shrink their size below $\bar{n}$ and, as a result, some of them become idle. Ultimately, in both scenarios, only high productivity plants operate in the new steady state.

The different stages of production during the transition generate interesting dynamics for factor income shares. To illustrate this, I first relate the plant profit shares to the aggregate capital income share. Let $\pi_{i, t}$ and $\phi_{i, t}$ denote total profits and the profit share for a $z_{i}$-plant at time $t$. Then $\phi_{i, t}=\pi_{i, t} / y_{i, t}$.

Proposition 4 The plant profit shares satisfy $\phi_{i, t} \leq \theta$ for $i \in\{H, L\}$ and for all $t$, where equality holds if $n_{i, t}>\bar{n}$.

Proof. Follows from plant profit maximization. See Appendix A.3.

\footnotetext{
${ }^{19}$ If $\bar{n}$ is low enough, it is possible that low productivity plants always hire more than $\bar{n}$ units of labor (i.e. the minimum requirement constraint never binds in equilibrium). In this case, all $z_{L}$-plants operate during the transition and they exit the economy as they depreciate. This is in contrast to data from Eastern European economies where plants were shut down during the transition. In numerical experiments, the choice of $\bar{n}$ allows for low productivity plants to shut down during the transition (see Section 5.1).

${ }^{20}$ Recall that $\alpha \equiv\left((1-\theta) z_{H} / z_{L}\right)^{1 / \theta}$, so $\alpha>1$ is equivalent to $z_{H} / z_{L}>1 /(1-\theta)$. For $\theta=0.34, \alpha>1$ if the high productivity technology is about 50 percent more productive than the low productivity technology. The choice of $\alpha$ in numerical experiments is discussed in Section 5.1.
} 
If the minimum labor constraint does not bind, the plant labor productivity is proportional to the wage rate and the plant profit share is constant. However, if plants are constrained to hire $\bar{n}$ units of labor, they hire more labor than in an unconstrained optimum, and, as a result, the profit share is lower than $\theta$.

In this economy, all high productivity plants operate throughout the transition and they hire more than the minimum required labor. Hence, $\phi_{H, t}=\theta$ for all $t$. Low productivity plants initially hire more than $\bar{n}$ units of labor, but later switch to operating at the minimum scale, as more and more labor is hired at the $z_{H}$-plants. Thus, $\phi_{L, t} \leq \theta$ with strict inequality for some $t$.

Let $\phi_{t}$ denote the aggregate capital income share at time $t$. Then, $\phi_{t}=\left(\Pi_{H, t}+\Pi_{L, t}\right) / Y_{t}$, where $\Pi_{i, t}$ are the total profits for plants of type $z_{i}$ at time $t$ and $Y_{t}$ is the aggregate output at $t$. Letting $Y_{i, t}$ be the total output produced by plants of type $z_{i}$ at $t$, the aggregate capital income share can also be written as:

$$
\begin{aligned}
\phi_{t} & =\frac{\Pi_{H, t}}{Y_{H, t}} \frac{Y_{H, t}}{Y_{t}}+\frac{\Pi_{L, t}}{Y_{L, t}} \frac{Y_{L, t}}{Y_{t}} \\
\phi_{t} & =\phi_{H, t} \frac{Y_{H, t}}{Y_{t}}+\phi_{L, t} \frac{Y_{L, t}}{Y_{t}}
\end{aligned}
$$

The second equality is obtained using $\Pi_{i, t} / Y_{i, t}=\pi_{i, t} M_{i, t} / y_{i, t} M_{i, t}=\phi_{i, t}$ for all $i$, and for all $t$. Moreover, using the result $\phi_{H, t}=\theta$ for all $t$, the aggregate capital income share is:

$$
\phi_{t}=\theta-\left(\theta-\phi_{L, t}\right) \frac{Y_{L, t}}{Y_{t}}
$$

Equation (13) shows that if the profit share of $z_{L}$-plants is equal to $\theta$ or the total output produced by these plants is zero, the aggregate capital income share is constant and equal to $\theta$. However, if $\phi_{L, t}<\theta$ and $Y_{L, t}>0$ then $\phi<\theta$.

The non-convexity in the plant-level technology is key in delivering variation in the capital share in the economy. Recall that low productivity plants have a profit share lower than $\theta$ whenever they hire only $\bar{n}$ units of labor (Proposition 4). Hence, the capital income share of this economy is lower than $\theta$ in two cases: $(i)$ all low productivity plants operate and they hire $\bar{n}$ labor, or $(i i)$ only some low productivity plants operate and hire $\bar{n}$ labor.

The dynamics of the aggregate capital income share are shown in Figure 3. The left side panel plots the aggregate capital share in an economy with $\alpha>1$. Initially, all plants operate and hire more than $\bar{n}$ units of labor and the aggregate capital share equals $\theta$. As the stock of $z_{H}$-plants accumulates over time, the low productivity plants reduce their scale. First all $z_{L}$-plants operate at $\bar{n}$, then some of them stop operating. During this process, the 
capital income share falls below $\theta$. In periods when some $z_{L}$-plants are idle, they earn no rents because they are not a scarce input in production. The capital share increases rapidly during these periods, as the economy gets rid of plants with a low profit share. In the steady state of the economy, the capital share is constant again and equal to $\theta$. The U-shaped dynamics for the aggregate capital share are slightly different when $\alpha<1$ (see the right side panel of Figure 3). As discussed previously, when the productivity difference between the two types of plants is smaller, so that $\alpha<1$, all $z_{L}$-plants operate throughout the transition and they exit the economy as they depreciate. The aggregate capital share drops below $\theta$ as low productivity plants operate at the corner. As the economy replaces these plants, the capital share returns gradually to the value $\theta$.

\subsection{Technology Change, Transfers and Wage Markups}

Here I discuss the predictions of an economy that undergoes technology change, has perfectly competitive wages, but receives transfers from abroad, i.e. $\overline{T r}_{t}>0$ and $\bar{\nu}_{t}=1$ for all $t$.

Suppose there are no transfers at time $t=0$, and there is a permanent increase in the flow of transfers starting at time $t=1$, so that $\overline{T r}_{t}=\overline{T r}_{1}>0$ for all $t \geq 1$. The consumers are richer, and as a result the labor input is lower compared to a model with no transfers. There is a drop in labor at time $t=1$ due to the introduction of the policy. If transfers are large enough, the drop in labor is associated with a negative growth in output from time $t=0$ to $t=1$. Following the introduction of transfers, the stock of high productivity capital accumulates faster in this economy leading to higher output growth compared to an economy with zero transfers.

The aggregate capital income share has U-shape dynamics as discussed in Section 4.1. Compared to a model with zero transfers, the decline in the capital share may occur sooner in the transition and may be of a larger magnitude (see Figure 4). An economy with transfers has lower aggregate labor and each plant's labor input, $n_{i, t}$, is lower. If transfers are large enough, low productivity plants operate at the minimum scale $\bar{n}$ sooner than in a model with zero transfers. The profit share at these plants declines and the economy's capital share is less than $\theta$, earlier in the transition.

Moreover, the decline in the capital share may be of larger magnitude in the economy with transfers. Recall that the capital share is $\phi=\theta-\left(\theta-\phi_{L, t}\right) \frac{Y_{L, t}}{Y_{t}}$. First, the profit share of low productivity plants, $\phi_{L, t}$, is lower compared to a model with zero transfers. When $z_{L}$-plants operate at $\bar{n}$, they have a fixed output given by $z_{L} \bar{n}^{1-\theta}$. The higher wage rate that prevails in an economy with transfers thus leads to lower profits, $\pi_{L, t}=z_{L} \bar{n}^{1-\theta}-w_{t} \bar{n}$, and a lower profit share. Second, the share of output produced by low productivity plants, $Y_{L, t} / Y_{t}$, 
is higher compared to a model with zero transfers. The $z_{H}$-plants decrease their optimal labor input and hence their output in response to the higher wages. Low productivity plants are constrained to operate at $\bar{n}$. All else equal, this leads to a larger share of output being produced by low productivity plants.

Now consider an economy that undergoes technology change, receives no transfers from the rest of the world but has wage markups. Wages are perfectly competitive at time $t=0$, and the government mandates a permanent increase in wage markups at time $t=1$. That is, $\bar{\nu}_{0}=1, \bar{\nu}_{t}<1$ for all $t \geq 1$. The economy with wage markups has lower growth rates of output during the transition to the steady state compared to a perfectly competitive economy. Wage markups depress the labor input and the accumulation of capital and lead to an increase in the wage rate. The dynamics of the aggregate capital share are similar to those present in an economy with transfers (see Figure 4).

\subsection{Nonlinearities}

In section 4.2, I discussed in turn the impact of transfers and wage markups on the aggregate capital income share. Here, I show by means of numerical experiments that the capital income share is a concave function of the policies. This implies that, the impact of the two policies on the capital income share may be nonlinear. This illustration is important in understanding the quantitative results shown in Section 5.

Consider an economy as described in Section 3. Let transfers be initially zero, $\overline{T r}_{0}=0$, and then a fixed percent of gross domestic product, $\overline{T r}_{t}=\overline{T r}$ for all $t \geq 1$. Let wage markups be initially null, $\bar{\nu}_{0}=1$, and then fixed at $1 / \bar{\nu}_{t}$ for all $t \geq 1$. Let $\overline{T r} \in\{0,1,2, \ldots 75\}$ and

let $\bar{\nu}_{t} \in\{1,0.76\}$. For each pair of policies, $\left(\overline{T r}_{t}, \bar{\nu}_{t}\right)_{t=0}^{\infty}$, and for a fixed set of parameters, I compute the equilibrium path for the capital income share. Next, I pick a time period $t$ and I compare the model's capital income share at time $t$ under different levels of transfers and wage markups.

The solid line in Figure 5 plots the capital income share at time $t=3$ as a function of transfers in an economy with no wage markups (i.e. $\bar{\nu}_{t}=1$ for all $t$ ). The dashed line plots the capital income share as transfers vary when the wage markup is 1.3 for all $t \geq 1$. In an economy with no markups and transfers of $30 \%$ of GDP, the capital income share at $t=3$ is 0.335 (see point $A$ in Figure 5 ). An economy with wage markup $1 / \bar{\nu}_{t}=1.3$ and no transfers has a capital income share equal to 0.316 (see point $B$ in the graph). However, point $C$ shows that the capital share in an economy with both policies is 0.267 . If the policies were to have an additive effect on the capital share, one would expect the dashed line in the figure to be parallel to the solid line and the capital share marked by point $C$ to be about 0.31 . 
The nonlinear effects observed are driven by asymmetric responses of the different plants to the policies. Larger transfers or higher markups lead to increases in the wage and depress aggregate labor. As a result, high productivity plants always lower their labor input and maintain a capital share of $\theta$. However, low productivity plants are forced to keep labor at $\bar{n}$ in order to produce positive output and thus have a profit share lower than $\theta$. With large transfers and large wage markups: $(i)$ a higher fraction of total output is produced by the low productivity plants and $(i i)$ the profit share of these plants declines. These two effects amplify each other since the aggregate capital share is given by $\phi=\theta-\left(\theta-\phi_{L, t}\right) Y_{L, t} / Y_{t}$ (see section 4.1 for derivation). Thus, policies affect the aggregate capital share in a nonlinear fashion.

\section{Quantitative Analysis}

In this section, I choose parameters based on national accounts data and revenue statistics. I show that the model's equilibrium paths line up well with East German data on output, expenditure shares, factor income shares, and hours worked. I then perform a counterfactual experiment. I remove the government-mandated wage increases and use the model to make predictions about output growth and factor income shares. Lastly, I perform experiments for Poland.

\subsection{Parameter Choices}

Table 2 summarizes the values of the model's parameters (see appendix A.1 for data sources). The economy specific parameters are the transfers, wage markups, tax rates, as well as the productivity level $z_{L}$.

Tax rates on consumption, labor income and capital income are computed using the methodology of Mendoza, Razin, and Tesar (1994). In the model, tax rates do not vary over time. For East Germany, they are set to the average tax rates for Germany over the period 1990 - 2005. For Poland, I use average tax rates for the period 1995 - 2005, due to data availability. The productivity level $z_{L}$ is set to match the initial level of output in the two economies.

The steady state capital income share, $\theta$, is set to the 1991 to 2006 average for unified Germany (see equation 1 for details on the computation). The capital share of West Germany is fairly constant over time. East Germany is small relative to the West and its large capital share variation has a very small impact on the share for unified Germany. The annual depreciation rate of the capital stocks is set to be the same for both stocks and it is consistent 
with the investment and capital stock data for Germany. The discount factor is chosen so that the annual real interest rate is $4 \%$.

The initial capital stocks for East Germany are determined as follows. I set the stock of high productivity plants to zero in 1989. This is consistent with the idea that the physical capital was outdated. I set the stock of low productivity plants to 3.5 times the size of GDP in 1989. Sinn and Sinn (1992) document that the net stock of fixed assets (excluding land) in 1989 was somewhere between 1.6 times GDP and 4.9 times GDP. The high end estimate is based on an exchange rate of 1 to 1 between the Mark and and Deutsche Mark, and, as they point out, it probably did not represent the true market value of capital. The low range estimate is obtained by writing off $67 \%$ of the capital stock to accommodate the West German accounting rules. ${ }^{21}$ In the model, the stock of low productivity plants becomes outdated once the new technology is available, and there are no further investments into it. This stock depreciates gradually over time. To be consistent with the model, I do not use the low end estimate of the capital-output ratio because it takes some depreciation into account.

The parameter $\bar{n}$ is a key parameter of the model. As indicated in Proposition 3, for a steady state to exist, $\bar{n}$ needs to be such that $N^{*} \geq M_{H}^{*} \bar{n}$ where $*$ denotes steady state. Equivalently, $\bar{n} \leq\left[\frac{z_{H} \theta\left(1-\tau_{M}\right)}{\beta^{-1}-1+\left(1-\tau_{M}\right) \delta_{H}}\right]^{1 /(\theta-1)}$. For very low values of $\bar{n}$ the model is not very interesting: all $z_{L}$-plants would operate during the transition $\left(n_{L}>\bar{n}\right)$ and they would ultimately disappear only because the stock depreciates. I pick $\bar{n} \simeq N^{*} / M_{H}^{*}$. This choice allows low productivity plants to hit the minimum labor constraint and shut down earlier in the transition.

The utility function used in the numerical experiments is $U(C, l)=\log (C)+\psi \log (1-l)$. The parameters $\psi, z_{H}, \bar{\nu}_{t}$ are chosen so that the model matches the level of aggregate hours ${ }^{22}$

\footnotetext{
${ }^{21}$ For a discussion of the capital stock in East Germany see Sinn and Sinn (1992, pp. 43-44). Also see their Appendix A on pages 214-216, for the data needed to compute the capital-output ratio.

22 Aggregate hours worked by a working-age person are computed as follows:

$$
\frac{H}{\text { Population } 15-64}=\frac{H}{E} * \frac{E}{\text { Population } 15-64} \text {, }
$$

where $H$ denotes total hours worked and $E$ denotes total employment. I compute an estimate of aggregate hours in 1989 using data on aggregate hours in 1991, as well as estimates of changes in $H / E, E$ and population over the two year period.

In 1991, the employment rate in East Germany was $70 \%$ and an employed person worked about 1,540 hours per year. This gives an average of 1,080 hours per year per working-age person or, relative to 52 weeks in a year, about 20.7 hours a week. To compute aggregate hours in 1989, I use data provided in a few studies. Dornbusch and Wolf (1994) report a 26.5\% drop in total employment in East Germany from 1989 to 1991 . Krueger and Pischke (1995) report a similar number. Over the same period, population ages 15 - 64 shrank by 3\% (see Appendix A.1 for data sources). Moreover, hours worked by employed persons declined by about $4.5 \%$ as reported by Bird, Schwarze, and Wagner (1994). I obtain an estimate of 28.7 hours worked per week in 1989.
} 
in East Germany in 1989, the increase in total factor productivity ${ }^{23}$ in East Germany from 1991 to 2006 and the large wage increases observed early in the transition. I set $\bar{\nu}_{1989}=1$. I pick $\bar{\nu}_{1990}<1$ and $\bar{\nu}_{1991}<1$ so that the model matches the wage increases between 1989 and 1991 documented in Table 1. Thereafter, I keep markups $1 / \bar{\nu}_{t}$ unchanged (see Figure 6). In the Appendix A.2, I perform sensitivity analysis by allowing the wage markups, $1 / \bar{\nu}_{t}$, to decline gradually over time after the initial increase.

The transfers, $\overline{T r}_{t}$, to East Germany represent net transfers from West Germany as well as the European Union. Transfers are zero in model period 1989. Up to year 2002, I use estimates of total net transfers provided by the European Commission. Beginning 2002, I let model transfers decline over time and I assume they reach zero in 2019 (see Figure 6). The Solidarity Pact II signed by the federal states and aimed at promoting the development of East Germany is scheduled to end in 2019. While this aid package is just a part of the transfers received by East Germany, I assume that by 2019 all other transfers will stop as well. In the Appendix A.2, I perform sensitivity analysis by allowing transfers to decline to zero farther in the future.

The transfers and wage markups for Poland are set in a similar fashion (see Figure 6). The transfers to Poland are taken from the data up until 2007, and are set to the average value of 1.5 percent of GDP thereafter. Given the recent accession to the EU, I consider that these transfers will not decline to zero in the near future.

\subsection{Predictions for East Germany}

I now use the parametrized model to examine the East German transition. Figure 7 plots the equilibrium paths of total factor productivity, hourly wages, GDP, the capital income share, hours worked and expenditure shares against East German data.

As discussed in Section 5.1, the parameters were chosen such that the model delivers an increase in TFP of about 30\% between 1991 and 2006, consistent with East German data (see top left panel in Figure 7). The model's total factor productivity grows endogenously over time during the transition. The economy accumulates the more productive plants gradually over time, and so, the model does not deliver the sharp increase in TFP observed in the data between 1991 to 1995. Moreover, recall that the model was parametrized to match the large increases in hourly wages between 1989 and 1991. However, the behavior of the wage rate following year 1991 is determined endogenously, and it matches the data well.

The middle left panel of Figure 7 compares the model's GDP with detrended data on

\footnotetext{
${ }^{23}$ The model's total factor productivity is calculated as the Solow residual from a standard Cobb-Douglas production function: $T F P_{t}=Y_{t} /\left[\left(M_{H, t}+M_{L, t}\right)^{\theta} N_{t}^{1-\theta}\right]$, where $M_{H, t}+M_{L, t}$ represents the total capital stock of the economy at time $t$. This is consistent with the calculation of TFP from data.
} 
GDP per working-age person. ${ }^{24}$ From 1989 to 1991, the model's output declines by 10\%, about one third of the decline observed in the data. This drop in output is driven by the decline in hours worked. ${ }^{25}$ First, the large increases in hourly wages between 1989 and 1991 depress hours worked in the model. Moreover, the transfers received generate a wealth effect which also leads to reductions in hours. Starting in 1991, output in the model grows. The initial output growth is lower than observed in East German data, because the productivity improvements in the model occur gradually, as discussed previously. However, the overall output growth in the model over the period 1991 - 2006 is very similar to the data.

The model predicts a time-varying capital income share, as observed in the middle right panel of Figure 7. The capital share is equal to $\theta=0.34$ in the first two years of the transition. Afterwards, due to the accumulation of the more productive technology, the low productivity plants are operated at the minimum scale. The transfers and wage increases raise the cost of labor and reduce the profits of the $z_{L}$-plants further. As a result, the capital share declines (see Section 4 for more detail). The model delivers a 10 percentage points drop in the capital share between 1990 and 1991. The capital share is 0.24 in 1991 and starts increasing as less output in the economy is produced by the $z_{L}$-plants. The model predicts that by 2005 the economy will not use any low productivity plants for production. The stock $M_{L}$ is not completely depreciated by that time, but the remaining plants are left idle.

The bottom panels in Figure 7 show the model's predictions for hours worked and expenditure shares. The large transfers and wage increases contribute to a $29 \%$ decline in hours worked between 1989 and 1991. This is in line with East German data (see footnote 22 for details on the construction of hours worked in the data). After 1991, the model predicts a slight increase in hours due to the decline in transfers over time.

Last but not least, the model's predictions for expenditure shares match the data. Since unification, East Germans have consumed and invested a lot more than they have produced, as measured by the economy's gross domestic product. In particular, the average consumption to output ratio was about 1.02 over the period 1991 to 2006, while the average investment to output ratio was about 0.35 . This was made possible through the large transfers received. In the model, transfers are available for consumption and investment. Most

\footnotetext{
${ }^{24}$ Gross domestic product per population aged $15-64$ is detrended with an annual trend growth of 1.013. The model does not have exogenous growth in technology or population, so the transformation is necessary to make data and model comparable. The choice of 1.3 percent annual trend growth corresponds to the growth rate of output per working-age person in West Germany since 1990.

${ }^{25}$ In the model, changes in the capital stock do not contribute to depressing output. The total capital stock of the economy, $M_{L, t}+M_{H, t}$, decreases slighlty initially. However, what matters for output in the initial two years of transition is a productivity-adjusted measure of capital, $\rho M_{H}+M_{L}$, which does not decline (Recall that the economy starts out with no $z_{H}$-plants. The model's output in 1989 and 1990 is given by $F\left(N, M_{H}, M_{L}\right)=z_{L}\left(\rho M_{H}+M_{L}\right)^{\theta} N^{1-\theta}$, as seen in the first branch of (4)).
} 
transfers get allocated to consumption, and only some go to investment, consistent with data observations. The model delivers an average consumption share of output of 1 and an average investment share of 0.33 for the period 1991 to 2006. The counterparts in a model with no transfers (i.e. $\overline{\operatorname{Tr}}_{t}=0$ for all $t$ ) are a consumption-output ratio of about $73 \%$ and an investment-output ratio of about $27 \%$.

I have shown that the model with transfers and wage markups performs well in accounting for key facts of the East German transition. Next, I perform a counterfactual experiment. I remove the government-mandated wage increases from the model (i.e. I set $\bar{\nu}_{t}=1$ for all $t$ ), and I examine the predictions for output, the capital income share, hours worked and expenditure shares. The results are shown in Figure 8. This experiment with the transfer policy alone delivers a smaller decline in hours worked and a smaller drop in output early in the transition. Throughout the transition, hours are higher and the $z_{H}$-plants accumulate faster. As a result, the East German GDP per working-age person grows by more, compared to the experiment with both policies. Moreover, as seen in the top right panel of Figure 8, the variations in the capital income share are smaller compared to the previous experiment. The capital income share is 0.33 in 1991 compared to 0.24 in the experiment with transfers and wage markups.

The success of the model in delivering a large initial drop in the capital share for East Germany is due to the government policies. ${ }^{26}$ In an experiment without transfers or wage markups (i.e. $\overline{T r}_{t}=0$ and $\bar{\nu}_{t}=1$ for all $t$ ), the capital income share varies by at most 5 percentage points throughout the transition. These variations occur due to the change in technology. Introducing either of the two policies in the model yields further declines in the capital share through the mechanisms described in Section 4.2. The experiment with the East German transfers alone delivers a capital share of 0.33 in 1991, as seen in Figure 8. An experiment with the East German wage markups alone delivers a capital share of 0.30 in 1991. However, when the two policies are considered together they have a nonlinear impact on the capital income share as described in section 4.3. The result is a capital share of 0.24 in 1991, as seen in the experiment with both policies (see Figure 7 or 8).

\subsection{Predictions for Poland}

Unlike East Germany, Poland received small transfers from the rest of the world and had more moderate wage growth throughout the transition (see Figure 6 and Table 1). The model's predictions for Poland are plotted in Figure 9. As seen in the top left panel of the

\footnotetext{
${ }^{26}$ As emphasized previously, the non-convexity in the plant-level production technology is key in allowing for variation in the capital share. In a model without this non-convexity, the government policies have no effect on the capital share.
} 
figure, the model is unsuccessful in delivering a decline in GDP per working-age person for Poland in the first years of the transition. Recall that the drop in output observed for East Germany is due to the decline in hours worked. While the model accounts for the decline in hours worked observed in Poland, this decline is smaller compared to East Germany, and is offset entirely by the increase in the capital stock. Hence, there is no drop in GDP in the model.

Earlier, I showed that transfers and government-mandated wage increases contributed to lowering the capital income share in East Germany. For Poland, the model's capital income share varies very little during the transition, as seen in the top right panel of Figure 9 . These variations are due to technology change, while the contributions of the two policies are fairly unimportant. The model performs fairly well in this regard. ${ }^{27}$ Regarding the expenditure shares, the model predicts a relatively high investment to output ratio early in the transition, as the economy accumulates the stock of $z_{H}$-plants.

The results for Poland are in contrast to those observed for East Germany. They highlight the fact that the large transfers and wage increases observed in East Germany contributed to a sizable decline in output and in the capital share early in the transition.

\section{Conclusions}

I examined the implications of two government policies on East Germany's output growth and factor income shares, in a model with embodied technological change. Transfers have a positive impact on output growth because they allow for more capital investment. Labor market policies such as government-mandated wage increases have a negative impact on capital accumulation, labor supply and output growth. The two policies generate somewhat offsetting effects on output growth and thus reveal why East Germany did not experience a growth miracle, in spite of the extensive support it received since early 1990s. In addition, the predictions for factor income shares are in line with East German data showing an initially low capital share that rises throughout the transition.

It is well documented that in many countries the shares of income accruing to capital and labor are fairly constant, but show small variations over time. In the model presented here, the transition to a higher productivity technology leads to endogenous variations in the capital income share. These variations arise due to a non-convexity in the plant level production technology, and are amplified by the government policies considered. While the paper analyzes transition economies, the findings on the capital share have potential for a wider applicability. Technology change induces relatively small variation in the model's

\footnotetext{
${ }^{27}$ See footnote 8 for details on the increase in Poland's capital income share since 2004.
} 
capital share. This mechanism could be useful in accounting for some of the variations in factor income shares observed in the U.S. and other economies.

\section{A.1 Data Appendix}

The data used in this paper were collected from several sources: $(i)$ Regional Accounts data from the German Statistical Offices, abbreviated henceforth as VGRdL (Statistisches Ämter Der Bundes und Der Länder, Volkswirtschaftliche Gesamtrechnungen der Länder available at: http://www.statistik-bw.de/Arbeitskreis_VGR), (ii) the Groningen Growth and Development Centre and the Conference Board, Total Economy Database, abbreviated henceforth as GGDC (available at: http://www.ggdc.net), (iii) the Organization for Economic Co-operation and Development, abbreviated henceforth as OECD (national accounts available at: www.sourceoecd.org and labor force statistics available at http://stats.oecd.org) and (iv) the Federal Statistical Office of Germany, abbreviated henceforth Destatis (Statistisches Bundesamt Deutschland, available at http://www.destatis.de/e_home.htm, Genesis Online Database).

Data for East Germany from the German statistical agencies is data for the five Länder: Brandenburg, Mecklenburg-Vorpommern, Sachsen, Sachsen-Anhalt and Thüringen. East Berlin is not included due to lack of data.

Gross domestic product (GDP) expressed in dollars at purchasing power parities for East Germany is constructed using data from VGRdL and GGDC. The growth rates of real GDP from the two sources are fairly similar for the years where there is overlap, so I use the level given by GGDC for years 1989 - 1991 and the growth rates provided by VGRdL thereafter. For Poland, GDP data is from GGDC (OECD data gives the same growth).

Data on population of ages 15 to 64 for East Germany is obtained from Destatis starting 1991 (Series 12411 - 0011, Bevölkerung: Bundesländer, Stichtag, Altersjahre). For 1989 and 1990, I use data from Statistical Yearbooks of the Democratic Republic (Statistisches Jahrbuch Der Deutschen Demokratischen Republik). Population data for Poland is from OECD.

I compute the capital income share using the formula in equation 1. For East Germany, I use data from VGRdL, Excel Table "Production, distribution and use of the gross domestic product in Germany by Bundesland and East West Regions 1991 to 2008". To obtain an estimate for the labor income of the self-employed, I assume that each self-employed person earns the average employees' compensation. This imputation method was suggested by Gollin (2002, p. 468). For Poland, I use data from OECD.

To construct hourly wage rates starting 1991, I use data on compensation of employees 
and total hours worked by employees. The nominal wage rates obtained are then deflated using the consumption deflator from the national accounts. For East Germany, I use data from VGRdL. To obtain total hours worked prior to 1997, I also use data on annual hours worked per employed person from OECD. For Poland, I use data from GGDC and OECD.

I also construct hours worked per working-age person starting 1989 for a number of other transition economies using the following sources: GGDC for total hours worked and World Development Indicators (available at: http://www.worldbank.org/ under "Data and Research") for population $15-64$.

Net transfers from the rest of the world for East Germany are obtained from European Commission (2002) and Jensen (2004). Transfers as a percent of East German GDP are also reported in Ross (2001). Net transfers for Poland are obtained from OECD national accounts, Table 4 "Disposable income, saving and net lending/net borrowing". For a discussion of the E.U. transfers to Poland also see Box 2.4 in OECD (2004).

\section{A.2 Sensitivity Analysis}

Wage markups and transfers are quantitatively important in accounting for the East German data presented in this paper. I perform sensitivity analysis for the choice of these exogenous time-varying inputs.

First, in the experiments performed in Section 5, the wage markups were unchanged starting 1991 (see Figure 6). Here, I consider wage markups that decline gradually over time. I keep the same wage markups for East Germany for years 1989 - 1991, but decrease the markups linearly thereafter, so that in year 2020 there is no markup $\left(\bar{\nu}_{2020}=1\right)$. The predictions from this experiment are nearly identical for the period 1989 to 2000 to the results plotted in Figure 7. The main difference is a smaller increase in wages. This leads to a larger increase in hours worked and a higher GDP per capita, both of which are quantitatively important after year 2000. The higher level of labor input that prevails in the model with declining markups means that $z_{L}$-plants are used in production for a longer time, and they exit the economy later. As a result, the capital income share in this model is a bit lower for years 2000 - 2006 compared to the values reported in Figure 7. The total factor productivity and the expenditure shares are quite similar between the two experiments.

Second, I perform sensitivity analysis by allowing transfers to decline to zero only ten years later, in year 2028. The predictions from this experiment are almost identical for the period 1989 to 2006 to the results plotted in Figure 7. The main differences in predictions occur after 2020, when due to positive transfers, the labor input will be lower. 


\section{A.3 Technical Appendix}

This appendix derives results from the paper. Section $A .3 .1$ derives the aggregate production function given in Proposition 1 in the paper. The decision rules for the plant labor inputs, $n_{H}$ and $n_{L}$, are derived simultaneously and are given in Corollary 1 . The steady state aggregate production function is given in Section A.3.2. Section A.3.3 derives properties of the plant profit shares given in Proposition 4 in the paper. Finally, Section A.3.4 derives equilibrium equations of the model.

\section{A.3.1 The Aggregate Production Function}

The aggregate production function has five branches depending on which types of plants operate and how much labor they employ. To simplify notation, I drop the time subscripts. Recall $z_{H}>z_{L}$.

Case 1: Suppose all plants operate and are allocated more than the minimum labor requirement. That is, $m_{i}=M_{i}$ for $i \in\{L, H\}$, and $n_{i}>\bar{n}$ for $i \in\{L, H\}$.

The aggregate production function is the solution to:

$$
\begin{gathered}
F\left(N, M_{H}, M_{L}\right)=\max _{\left\{n_{i}\right\}_{i \in\{H, L\}}} M_{H} z_{H} n_{H}^{1-\theta}+M_{L} z_{L} n_{L}^{1-\theta} \\
\text { s.t. } M_{H} n_{H}+M_{L} n_{L}=N
\end{gathered}
$$

The first order conditions yield:

$$
n_{H}=n_{L}\left(\frac{z_{H}}{z_{L}}\right)^{1 / \theta}
$$

Let $\rho \equiv\left(\frac{z_{H}}{z_{L}}\right)^{1 / \theta}$. Then $n_{H}=\rho n_{L}$. Using the feasibility constraint, I get

$$
n_{L}=\frac{N}{\rho M_{H}+M_{L}}
$$

I now use the expressions for the optimal $n_{H}$ and $n_{L}$ to obtain the expression for $F$.

$$
F\left(N, M_{H}, M_{L}\right)=z_{L} N^{1-\theta}\left(\rho M_{H}+M_{L}\right)^{\theta}
$$


Recall I assumed $n_{i}>\bar{n}$. These constraints imply:

$$
n_{L}=\frac{N}{\rho M_{H}+M_{L}}>\bar{n} \Leftrightarrow N>\left(\rho M_{H}+M_{L}\right) \bar{n}
$$

To summarize: If $N>\left(\rho M_{H}+M_{L}\right) \bar{n}$, then $F\left(N, M_{H}, M_{L}\right)=z_{L}\left(\rho M_{H}+M_{L}\right)^{\theta} N^{1-\theta}$.

Case 2. Suppose all plants operate. Suppose $z_{H}$-plants are allocated more than the minimum labor requirement, while $z_{L}$-plants operate at the minimum scale. That is, $m_{i}=M_{i}$ for $i \in\{L, H\}, n_{H}>\bar{n}$, and $n_{L}=\bar{n}$.

The aggregate production function is the solution to:

$$
\begin{gathered}
F\left(N, M_{H}, M_{L}\right)=\max _{n_{H}} M_{H} z_{H} n_{H}^{1-\theta}+M_{L} z_{L} \bar{n}^{1-\theta} \\
\text { s.t. } M_{H} n_{H}+M_{L} \bar{n}=N
\end{gathered}
$$

Solution for $n_{H}$ is:

$$
n_{H}=\frac{N-M_{L} \bar{n}}{M_{H}}
$$

The aggregate production function is given by:

$$
F\left(N, M_{H}, M_{L}\right)=z_{H} M_{H}^{\theta}\left(N-M_{L} \bar{n}\right)^{1-\theta}+z_{L} \bar{n}^{1-\theta} M_{L}
$$

The restriction $n_{H}>\bar{n}$ implies that:

$$
N>\left(M_{H}+M_{L}\right) \bar{n}
$$

To summarize: If $N>\left(M_{H}+M_{L}\right) \bar{n}$ then

$$
F\left(N, M_{H}, M_{L}\right)=z_{H} M_{H}^{\theta}\left(N-M_{L} \bar{n}\right)^{1-\theta}+z_{L} \bar{n}^{1-\theta} M_{L} \text {. }
$$

Case 3: Suppose all $z_{H}$-plants operate and are allocated at least the minimum labor requirement. Suppose only some $z_{L}$-plants operate and they operate at the minimum scale. That is, $m_{H}=M_{H}, 0<m_{L}<M_{L}, n_{H} \geq \bar{n}$, and $n_{L}=\bar{n}$.

The aggregate production function is the solution to:

$$
\begin{gathered}
F\left(N, M_{H}, M_{L}\right)=\max _{n_{H}, m_{L}} M_{H} z_{H} n_{H}^{1-\theta}+m_{L} z_{L} \bar{n}^{1-\theta} \\
\text { s.t. } M_{H} n_{H}+m_{L} \bar{n}=N
\end{gathered}
$$


The measure of low productivity plants that operate, $m_{L}$, is:

$$
m_{L}=\frac{N-M_{H} n_{H}}{\bar{n}}
$$

Then,

$$
F\left(N, M_{H}, M_{L}\right)=\max _{n_{H \geq \bar{n}}} M_{H} z_{H} n_{H}^{1-\theta}+\left(\frac{N}{\bar{n}}-\frac{M_{H} n_{H}}{\bar{n}}\right) z_{L} \bar{n}^{1-\theta}
$$

The first order condition yields:

$$
n_{H}=\left(\frac{(1-\theta) z_{H}}{z_{L}}\right)^{1 / \theta} \bar{n}
$$

Let $\alpha \equiv\left(\frac{(1-\theta) z_{H}}{z_{L}}\right)^{1 / \theta}$. Recall that I assumed $n_{H} \geq \bar{n}$. Thus, I obtain

$$
n_{H}=\max \{1, \alpha\} \bar{n}
$$

Moreover, the assumption $0<m_{L}<M_{L}$ becomes:

$$
\max \{1, \alpha\} M_{H} \bar{n}<N<\left[\max \{1, \alpha\} M_{H}+M_{L}\right] \bar{n}
$$

To summarize: If $\max \{1, \alpha\} M_{H} \bar{n}<N<\left[\max \{1, \alpha\} M_{H}+M_{L}\right] \bar{n}$, then $F\left(N, M_{H}, M_{L}\right)=\left[z_{L} \bar{n}^{-\theta}\right] N+\left[z_{H} \max \{1, \alpha\}^{1-\theta}-z_{L} \max \{1, \alpha\}\right] \bar{n}^{1-\theta} M_{H}$

Case 4. Suppose all $z_{H}$-plants operate and are allocated more than the minimum labor requirement. Suppose no $z_{L}$-plants operate. That is, $m_{H}=M_{H}, m_{L}=0, n_{H}>\bar{n}$, and $n_{L}=0$.

The aggregate production function is the solution to:

$$
\begin{gathered}
F\left(N, M_{H}, M_{L}\right)=\max _{n_{H}} M_{H} z_{H} n_{H}^{1-\theta} \\
\text { s.t. } M_{H} n_{H}=N
\end{gathered}
$$

The solution is $n_{H}=N / M_{H}$ and

$$
F\left(N, M_{H}, M_{L}\right)=z_{H} M_{H}^{\theta} N^{1-\theta}
$$

Recall I assumed $n_{H}>\bar{n}$. This implies that $N / M_{H}>\bar{n}$. Moreover, from Case 3 I know that if $\max \{1, \alpha\} M_{H} \bar{n}<N$ then $m_{L}>0$; hence, I can restrict $N \leq \max \{1, \alpha\} M_{H} \bar{n}$

To summarize: If $M_{H} \bar{n}<N \leq \max \{1, \alpha\} M_{H} \bar{n}$, then $F\left(N, M_{H}, M_{L}\right)=z_{H} M_{H}^{\theta} N^{1-\theta}$. 
Case 5. Suppose only some $z_{H}$-plants operate, they operate at the minimum scale. Suppose no $z_{L}$-plants operate. That is, $m_{H}<M_{H}, m_{L}=0, n_{H}=\bar{n}$, and $n_{L}=0$.

The aggregate production function is the solution to:

$$
\begin{gathered}
F\left(N, M_{H}, M_{L}\right)=\max _{m_{H}} m_{H} z_{H} \bar{n}^{1-\theta} \\
\text { s.t. } m_{H} \bar{n}=N
\end{gathered}
$$

The solution is $m_{H}=N / \bar{n}$ and

$$
F\left(N, M_{H}, M_{L}\right)=z_{H} \bar{n}^{-\theta} N
$$

Recall I assumed $m_{H}<M_{H}$. This implies $N / \bar{n}<M_{H}$.

To summarize: If $N<M_{H} \bar{n}$, then $F\left(N, M_{H}, M_{L}\right)=z_{H} \bar{n}^{-\theta} N$.

So far, I have derived that:

$$
\begin{aligned}
& F\left(N, M_{H}, M_{L}\right)= \\
& \begin{cases}f_{1} \equiv z_{L}\left(\rho M_{H}+M_{L}\right)^{\theta} N^{1-\theta} & \text { if } N>\left(\rho M_{H}+M_{L}\right) \bar{n} \\
f_{2} \equiv z_{H} M_{H}^{\theta}\left(N-M_{L} \bar{n}\right)^{1-\theta}+z_{L} \bar{n}^{1-\theta} M_{L} & \text { if } N>\left(M_{H}+M_{L}\right) \bar{n} \\
f_{3} \equiv A M_{H}+z_{L} \bar{n}^{-\theta} N & \text { if } G_{\alpha} M_{H} \bar{n} \leq N<\left(G_{\alpha} M_{H}+M_{L}\right) \bar{n} \\
f_{4} \equiv z_{H} M_{H}^{\theta} N^{1-\theta} & \text { if } M_{H} \bar{n} \leq N \leq G_{\alpha} M_{H} \bar{n} \\
f_{5} \equiv z_{H} \bar{n}^{-\theta} N & \text { if } N \leq M_{H} \bar{n}\end{cases}
\end{aligned}
$$

where $G_{\alpha} \equiv \max \{1, \alpha\}$ and $A=\left[z_{H}\left(G_{\alpha}\right)^{1-\theta}-z_{L} G_{\alpha}\right] \bar{n}^{1-\theta}$.

Next, it is easy to show that the following statements hold:

$$
\begin{aligned}
& f_{1}=f_{2} \text { if } N=\left(\rho M_{H}+M_{L}\right) \bar{n} \\
& f_{1}>f_{2} \text { if } N>\left(\rho M_{H}+M_{L}\right) \bar{n} \\
& f_{3}=f_{2} \text { if } N=\left(G_{\alpha} M_{H}+M_{L}\right) \bar{n} \\
& f_{3}>f_{2} \text { if } N \in\left(\left(M_{H}+M_{L}\right) \bar{n},\left(\alpha M_{H}+M_{L}\right) \bar{n}\right) \text { where } \alpha>1
\end{aligned}
$$

The expression in (14) together with the statements in (15) give the production function in Proposition (1) in the paper. 
Corollary 1 The decision rules for plant labor are given by:

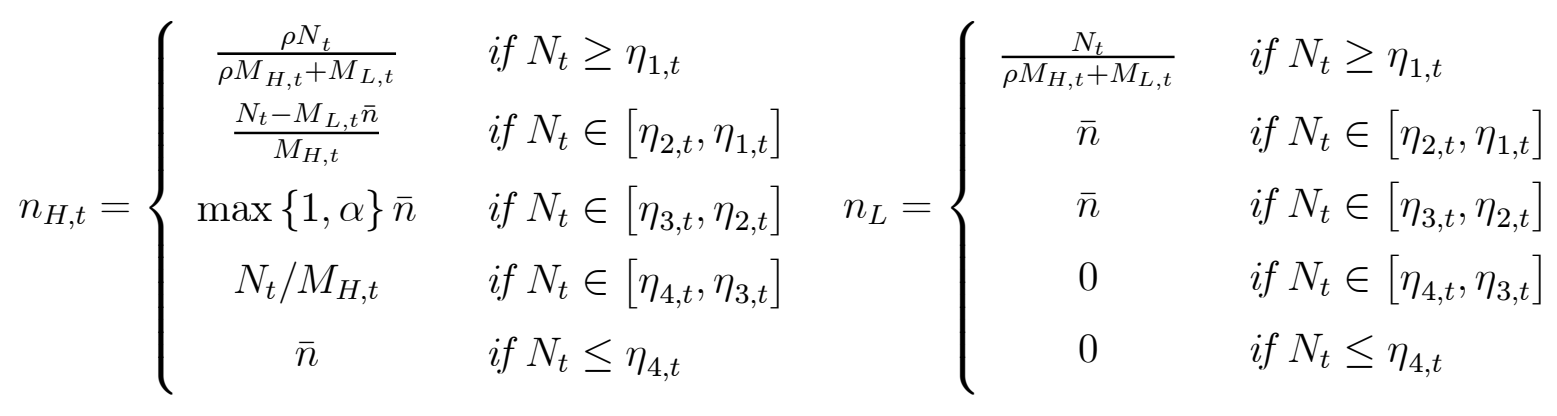

where $\eta_{1} \equiv\left(\rho M_{H, t}+M_{L, t}\right) \bar{n}, \eta_{2} \equiv\left(G_{\alpha} M_{H, t}+M_{L, t}\right) \bar{n}, \eta_{3} \equiv G_{\alpha} M_{H, t} \bar{n}, \eta_{4} \equiv M_{H, t} \bar{n}$ and where $G_{\alpha} \equiv \max \{1, \alpha\}$.

\section{A.3.2 The Steady State Aggregate Production Function}

During the transition the stock of $z_{L}$-plants depreciates over time while the more productive $z_{H}$-plants accumulate. Here I derive the limit of the aggregate production function as $M_{L, t} \rightarrow$ 0 . Notice that

$$
\begin{aligned}
\lim _{M_{L, t \rightarrow 0} \eta_{1, t}} & =\rho M_{H, t} \bar{n} \\
\lim _{M_{L, t} \rightarrow 0} \eta_{2, t} & =G_{\alpha} M_{H, t} \bar{n}=\eta_{3, t}
\end{aligned}
$$

The limit of the aggregate production function is:

$$
\lim _{M_{L, t} \rightarrow 0} F\left(N_{t}, M_{H, t}, M_{L, t}\right)= \begin{cases}z_{L} \rho^{\theta} M_{H, t}^{\theta} N_{t}^{1-\theta} & \text { if } N_{t} \geq \rho M_{H, t} \bar{n} \\ z_{H} M_{H, t}^{\theta} N_{t}^{1-\theta} & \text { if } G_{\alpha} M_{H, t} \bar{n} \leq N_{t} \leq \rho M_{H, t} \bar{n} \\ A M_{H, t}+z_{L} \bar{n}^{-\theta} N_{t} & \text { if } G_{\alpha} M_{H, t} \bar{n}=N_{t}=G_{\alpha} M_{H, t} \bar{n} \\ z_{H} M_{H, t}^{\theta} N_{t}^{1-\theta} & \text { if } M_{H, t} \bar{n} \leq N_{t} \leq G_{\alpha} M_{H, t} \bar{n} \\ z_{H} \bar{n}^{-\theta} N_{t} & \text { if } N_{t} \leq M_{H, t} \bar{n}\end{cases}
$$

where $G_{\alpha} \equiv \max \{1, \alpha\}$ and $A=\left[z_{H}\left(G_{\alpha}\right)^{1-\theta}-z_{L} G_{\alpha}\right] \bar{n}^{1-\theta}$.

Notice that as $M_{L} \rightarrow 0$ the third branch of the production function essentially collapses 
to one point. At $N_{t}=G_{\alpha} M_{H, t} \bar{n}$ the output is:

$$
\begin{aligned}
A M_{H, t}+z_{L} \bar{n}^{-\theta} N_{t} & =\left[z_{H}\left(G_{\alpha}\right)^{1-\theta}-z_{L} G_{\alpha}\right] \bar{n}^{1-\theta} M_{H, t}+z_{L} \bar{n}^{-\theta}\left(G_{\alpha} M_{H, t} \bar{n}\right) \\
& =z_{H}\left(G_{\alpha}\right)^{1-\theta} \bar{n}^{1-\theta} M_{H, t} \\
& =z_{H} M_{H, t}\left(\frac{N_{t}}{M_{H, t}}\right)^{1-\theta} \\
& =z_{H} M_{H, t}^{\theta} N_{t}^{1-\theta}
\end{aligned}
$$

Moreover, given the definition of $\rho$ I have $z_{L} \rho^{\theta}=z_{H}$. To summarize:

$$
\lim _{M_{L, t} \rightarrow 0} F\left(N_{t}, M_{H, t}, M_{L, t}\right)= \begin{cases}z_{H} M_{H, t}^{\theta} N_{t}^{1-\theta} & \text { if } N_{t} \geq M_{H, t} \bar{n} \\ z_{H} \bar{n}^{-\theta} N_{t} & \text { if } N_{t} \leq M_{H, t} \bar{n}\end{cases}
$$

\section{A.3.3 Plant Profit Shares}

I derive the result in Proposition 4 in the paper.

For each $t$, a plant of type $z_{i}$ maximizes profits subject to hiring at least $\bar{n}$ units of labor:

$$
\begin{gathered}
\pi_{i, t} \equiv \max _{n_{i, t}} z_{i} n_{i, t}^{1-\theta}-w_{t} n_{i, t} \\
\text { s.t. } n_{i, t} \geq \bar{n}
\end{gathered}
$$

The first order condition for this problem is $w_{t} \geq(1-\theta) z_{i} n_{i, t}^{-\theta}$, with equality if $n_{i, t}>\bar{n}$. Thus, profits of a plant of type $z_{i}$ at time $t$ are given by:

$$
\begin{aligned}
\pi_{i, t} & \leq z_{i} n_{i, t}^{1-\theta}-\left[(1-\theta) z_{i} n_{i, t}^{-\theta}\right] n_{i, t}=\theta z_{i} n_{i, t}^{1-\theta}=\theta y_{i, t}, \text { with equality if } n_{i, t}>\bar{n} . \\
\text { or, } \frac{\pi_{i, t}}{y_{i, t}} & =\phi_{i, t} \leq \theta, \text { with equality if } n_{i, t}>\bar{n} .
\end{aligned}
$$

\section{A.3.4 Intertemporal and Intratemporal Equilibrium Conditions}

Here I derive the first order conditions of the $j$ th union's problem. For the time being, I ignore the government's requirement that the markup be at most $1 / \bar{\nu}_{t}$. Let $\lambda_{t}(j)$ denote the Lagrange multiplier on the budget constraint at time $t$. The first order conditions of this problem are summarized by the budget constraints, the laws of motion for capital, 
$X_{L, t}(j)=0$, as well as:

$$
\begin{aligned}
\beta^{t} U_{C}\left[C_{t}(j), l_{t}(j)\right] & =\lambda_{t}(j) \cdot\left(1+\tau_{C, t}\right) \\
\beta^{t} U_{l}\left[C_{t}(j), l_{t}(j)\right] \frac{\partial l_{t}(j)}{\partial w_{t}(j)} & =-\lambda_{t}(j) \cdot\left(1-\tau_{N, t}\right)\left[l_{t}(j)+w_{t}(j) \frac{\partial l_{t}(j)}{\partial w_{t}(j)}\right] \\
\frac{\lambda_{t}(j)}{\lambda_{t+1}(j)} & =\left(1+\left(1-\tau_{M, t+1}\right)\left(r_{H, t+1}-\delta_{H}\right)\right)
\end{aligned}
$$

and the transversality condition: $\lim _{t \rightarrow \infty} \beta^{t} U_{C}\left[C_{t}(j), l_{t}(j)\right] M_{H, t+1}(j)=0$.

The Euler Equation is:

$$
\frac{U_{C}\left(C_{t}(j), l_{t}(j)\right)}{U_{C}\left(C_{t+1}(j), l_{t+1}(j)\right)}=\beta \frac{1+\tau_{C, t}}{1+\tau_{C, t+1}}\left(1+\left(1-\tau_{M, t+1}\right)\left(r_{H, t+1}-\delta_{H}\right)\right)
$$

In order to derive the intratemporal marginal rate of substitution between leisure and consumption I first derive $\partial l_{t}(j) / \partial w_{t}(j)$. Recall that the demand for labor of type $j$ is given by equation ( 7 ) in the paper:

$$
l_{t}(j)=\left(\frac{w_{t}}{w_{t}(j)}\right)^{1 /(1-\nu)} N_{t}
$$

Thus,

$$
\begin{aligned}
\frac{\partial l_{t}(j)}{\partial w_{t}(j)} & =w_{t}^{1 /(1-\nu)} N_{t} \frac{1}{\nu-1} w_{t}(j)^{1 /(\nu-1)-1} \\
& =\frac{1}{\nu-1} \frac{l_{t}(j)}{w_{t}(j)}
\end{aligned}
$$

Thus, equation (16) becomes:

$$
\begin{gathered}
\beta^{t} U_{l}\left[C_{t}(j), l_{t}(j)\right] \frac{1}{\nu-1} \frac{l_{t}(j)}{w_{t}(j)}=-\lambda_{t}\left(1-\tau_{N, t}\right) \frac{\nu}{\nu-1} l_{t}(j) \\
\Leftrightarrow \beta^{t} U_{l}\left[C_{t}(j), l_{t}(j)\right]=-\lambda_{t}\left(1-\tau_{N, t}\right) \nu w_{t}(j)
\end{gathered}
$$

The intratemporal condition may be written as:

$$
w_{t}(j)=-\frac{1}{\nu} \frac{\left(1+\tau_{C, t}\right)}{\left(1-\tau_{N, t}\right)} \frac{U_{l}\left[C_{t}(j), l_{t}(j)\right]}{U_{C}\left[C_{t}(j), l_{t}(j)\right]}
$$




\section{References}

Akerlof, G. A., A. K. Rose, J. L. Yellen, and H. Hessenius (1991): "East Germany in from the Cold: The Economic Aftermath of Currency Union," Brookings Papers on Economic Activity, 1991(1), 1-87.

Atkeson, A., And P. J. Kehoe (1993): "Industry Evolution and Transition: The Role of Information Capital," Federal Reserve Bank of Minneapolis, Staff Report, 162.

Bird, E. J., J. Schwarze, and G. G. Wagner (1994): "Wage Effects of the Move Toward Free Markets in East Germany," Industrial and Labor Relations Review, 47(3), 390-400.

Blanchard, O. J., S. Commander, and F. Coricelli (1995): "Unemployment and Restructuring in Eastern Europe and Russia," in Unemployment, Restructuring and the Labor Market in Eastern Europe and Russia, ed. by S. Commander, and F. Coricelli, pp. 289-329. The World Bank, Washington D.C.

Blanchard, O. J., and N. Kiyotaki (1987): "Monopolistic Competition and the Effects of Aggregate Demand," American Economic Review, 77, 647-666.

Blanchard, O. J., And M. Kremer (1997): "Disorganization," Quarterly Journal of Economics, 112, 1091-1126.

Boldrin, M., and M. Horvath (1995): "Labor Contracts and Business Cycles," Journal of Political Economy, 103(5), 972-1004.

Burda, M. C., And M. Funke (2001): "Wages and Structural Adjustment in the New German States," in Employment Policy in Transition: The Lessons of German Integration for the Labor Market, ed. by R. T. Riphahn, D. J. Snower, and K. F. Zimmermann, pp. 31-51. Berlin: Springer-Verlag.

Burda, M. C., And J. Hunt (2001): "From Reunification to Economic Integration: Productivity and the Labor Market in Eastern Germany," Brookings Papers on Economic Activity, 2001(2), 1-71.

Campos, N. F., and F. Coricelli (2002): "Growth in Transition: What We Know, What We Don't, and What We Should," Journal of Economic Literature, 40(3), 793-836.

Choi, S., and J.-V. Ríos-Rull (2008): "Understanding the Dynamics of Labor Share: The Role of Noncompetitive Factor Prices," Mimeo. 
Dornbusch, R., And H. W. Wolf (1994): "East German Economic Reconstruction," in The Transition in Eastern Europe, ed. by O. J. Blanchard, K. A. Froot, and J. D. Sachs, vol. 1, pp. 155-190. The University of Chicago Press.

European Commission (2002): "Germany's Growth Performance in the 1990s," Directorate General for Economic and Financial Affairs, Economic Papers No. 170.

Fischer, S., R. Sahay, and C. A. Végh (1996): "Economies in Transition: The Beginnings of Growth," American Economic Review, 86, 229-233.

Freeman, R. B. (1994): "What Direction for Labor Market Institutions in Eastern and Central Europe?," in The Transition in Eastern Europe, ed. by O. J. Blanchard, K. A. Froot, and J. D. Sachs, vol. 2, pp. 1-29. The University of Chicago Press.

Gollin, D. (2002): "Getting Income Shares Right," Journal of Political Economy, 110(2), $458-474$.

Gomme, P., And J. Greenwood (1995): "On the Cyclical Allocation of Risk," Journal of Economic Dynamics and Control, 19, 91-124.

Gorodnichenko, Y., E. G. Mendoza, and L. L. Tesar (2009): "The Finnish Great Depression: From Russia with Love," NBER Working Paper 14874.

Hansen, G. D., and E. C. Prescott (2005): "Capacity Constraints, Asymmetries and the Business Cycle," Review of Economic Dynamics, 8, 850-865.

Hoffmann, L. (1992): "Integrating East German States into the German Economy: Opportunities, Burdens and Options," in Economic Aspects of German Unification, ed. by P. J. J. Welfens, pp. 49-77. Heidelberg: Springer-Verlag.

Hornstein, A. (1993): "Monopolistic Competition, Increasing Returns to Scale, and the Importance of Productivity Shocks," Journal of Monetary Economics, 31(3), 299-316.

Hunt, J. (2001): "Post-Unification Wage Growth in East Germany," Review of Economics and Statistics, 83(1), 190-195.

Jensen, H. (2004): "Transfers to Germany's Eastern Lander: A Necessary Price for Convergence or a Permanent Drag?," European Commission Directorate General for Economic and Financial Affairs, Country Focus, 1(16). 
Kaldor, N. (1961): "Capital Accumulation and Economic Growth," in The Theory of Capital, ed. by F. A. Lutz, and D. C. Hague, pp. 177-222. New York: St. Martin's Press (for Internat. Econ. Assoc.).

Kravis, I. B. (1959): "Relative Income Shares in Fact and Theory," American Economic Review, 49(5), 917-949.

Krueger, A. B., and J.-S. Pischke (1995): "A Comparative Analysis of East and West German Labor Markets: Before and After Unification," in Differences and Changes in Wage Structures, ed. by R. B. Freeman, and L. F. Katz, pp. 405-455. The University of Chicago Press.

Mendoza, E. G., A. Razin, and L. L. Tesar (1994): "Effective Tax Rates in Macroeconomics: Cross-Country Estimates of Tax Rates on Factor Incomes and Consumption," Journal of Monetary Economics, 34(3), 297-323.

OECD (2004): "OECD Economic Surveys: Poland," Organization for Economic CoOperation and Development, 2004(8), 1-215.

Ríos-Rull, J.-V., and R. Santaeulàlia-Llopis (2009): "Redistributive Shocks and Productivity Shocks," Mimeo.

RodrIK, D. (1994): "Foreign Trade in Eastern Europe's Transition: Early Results," in The Transition in Eastern Europe, ed. by O. J. Blanchard, K. A. Froot, and J. D. Sachs, vol. 2, pp. 319-356. The University of Chicago Press.

Roland, G., and T. Verdier (1999): "Transition and the Output Fall," Economics of Transition, 7(1), 1-28.

Ross, M. (2001): "Transfers, Agglomeration and German Unification," Hamburg Institute of International Economics, Discussion Paper, 144.

Sachs, J. (1993): Poland's Jump to the Market Economy. The MIT Press, Cambridge, Massachusetts.

Sinn, G., And H.-W. Sinn (1992): Jumpstart: The Economic Unification of Germany. The MIT Press, Cambridge, Massachusetts.

Sinn, H.-W. (2007): Can Germany be Saved? The Malaise of the World's First Welfare State. The MIT Press, Cambridge, Massachusetts. 
United Nations (1988): "National Accounts Statistics: Main Aggregates and Detailed Tables," Part I, Publishing Division United Nations, New York, N.Y. 
Table 1: Hourly Wage Growth (Percent).

\begin{tabular}{rcc}
\hline \hline & East Germany & Poland \\
\cline { 2 - 3 } $1989-1990$ & 12.5 & negative \\
$1990-1991$ & 32.3 & 3 \\
$1991-1992$ & 16 & 18 \\
Average, $1992-2006$ & 2 & 2 \\
\hline
\end{tabular}

Notes: Wages used in the calculations are real unless otherwise noted. The deflator used is the consumption deflator from national accounts. East Germany: table reports nominal wage growth for 1989-1990 from Krueger and Pischke (1995), but, as they point out, this mostly reflects real changes due to a relatively stable average CPI. ${ }^{28}$ Data for $1990-1991$ is real hourly wage data from Hunt (2001). Poland: real wage growth over period 1989-1991 are from Blanchard, Commander, and Coricelli (1995). Hourly wage growth rates for 1991-2003 for both economies are based on my own calculations (see appendix A.1 for details on data sources).

\footnotetext{
${ }^{28}$ Akerlof, Rose, Yellen, and Hessenius (1991, Table 4) report that average CPI was almost unchanged through the end of 1990 . The figure of 12.5 percent is potentially an underestimate for hourly wage growth between 1989 and 1990, because hours worked declined during that period.
} 
Table 2: Model Parameters and Time-Varying Inputs

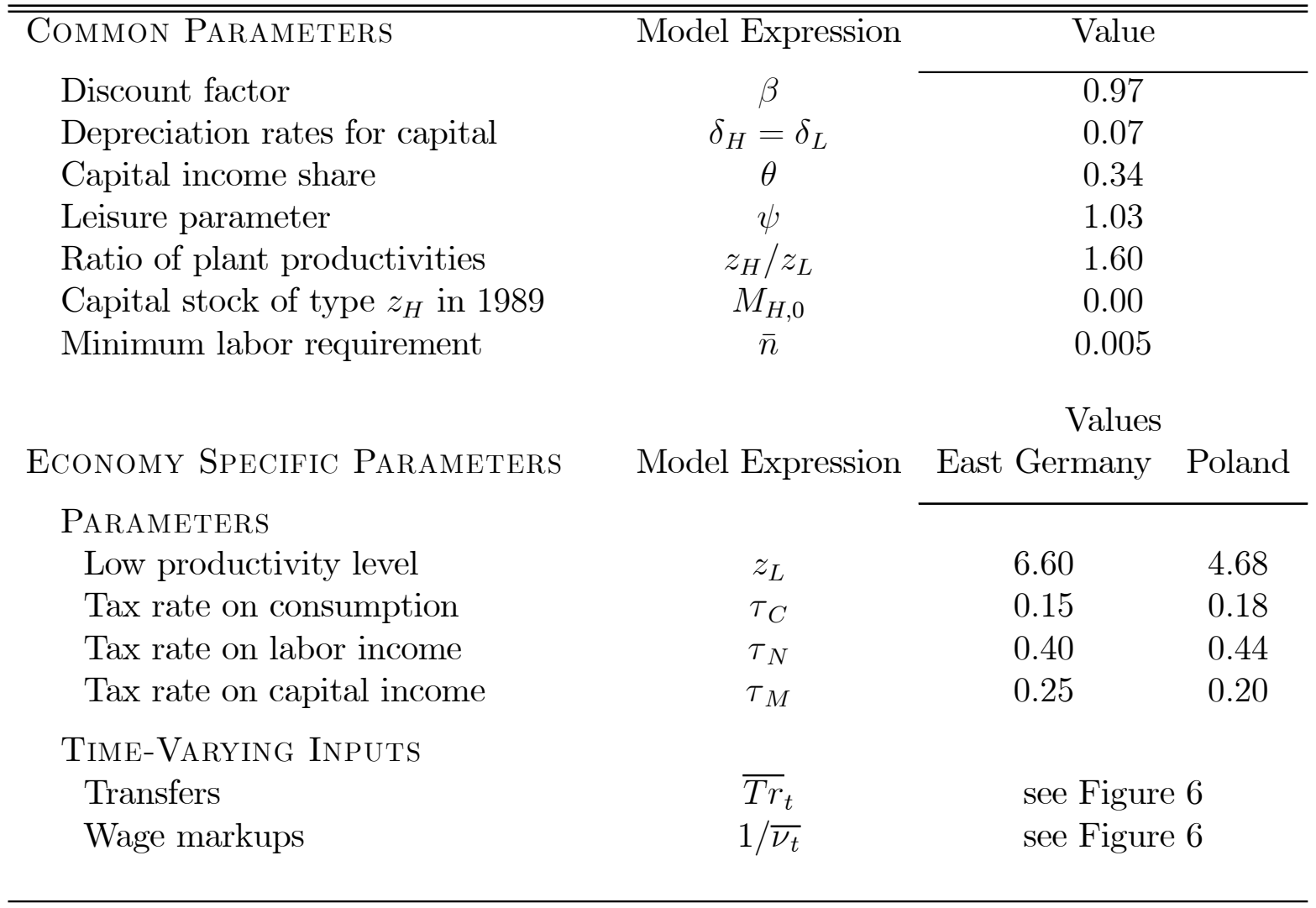


Figure 1: Gross Domestic Product Per Working-Age Person

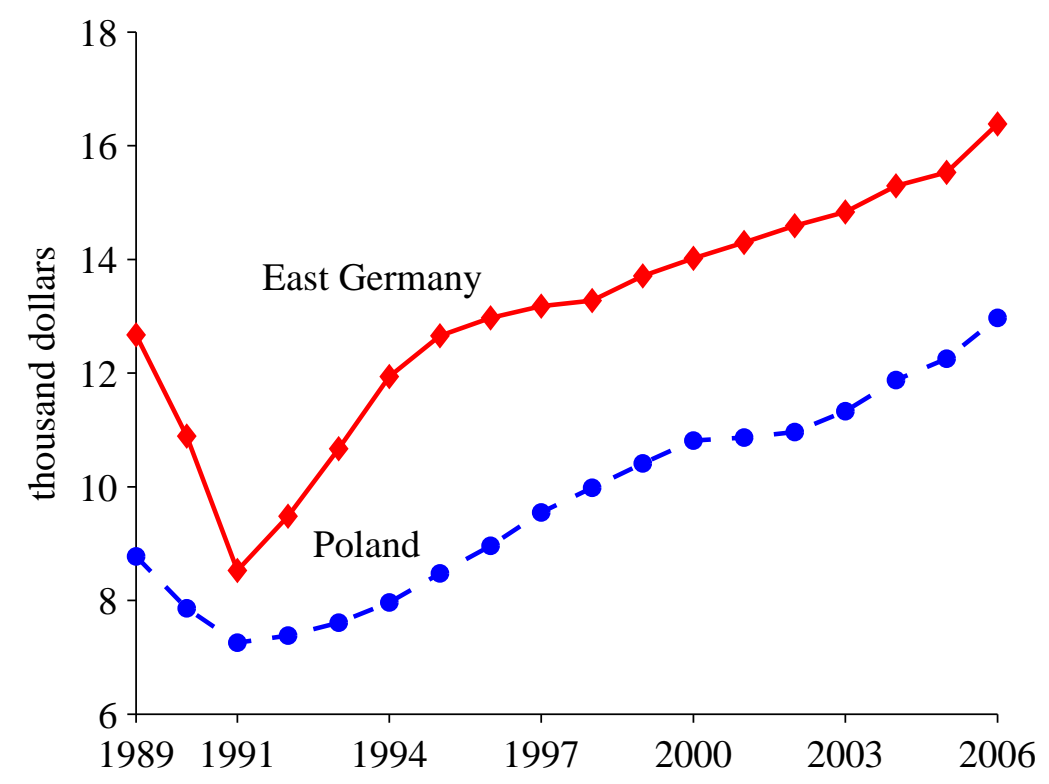

Figure 2: The Capital Income Share

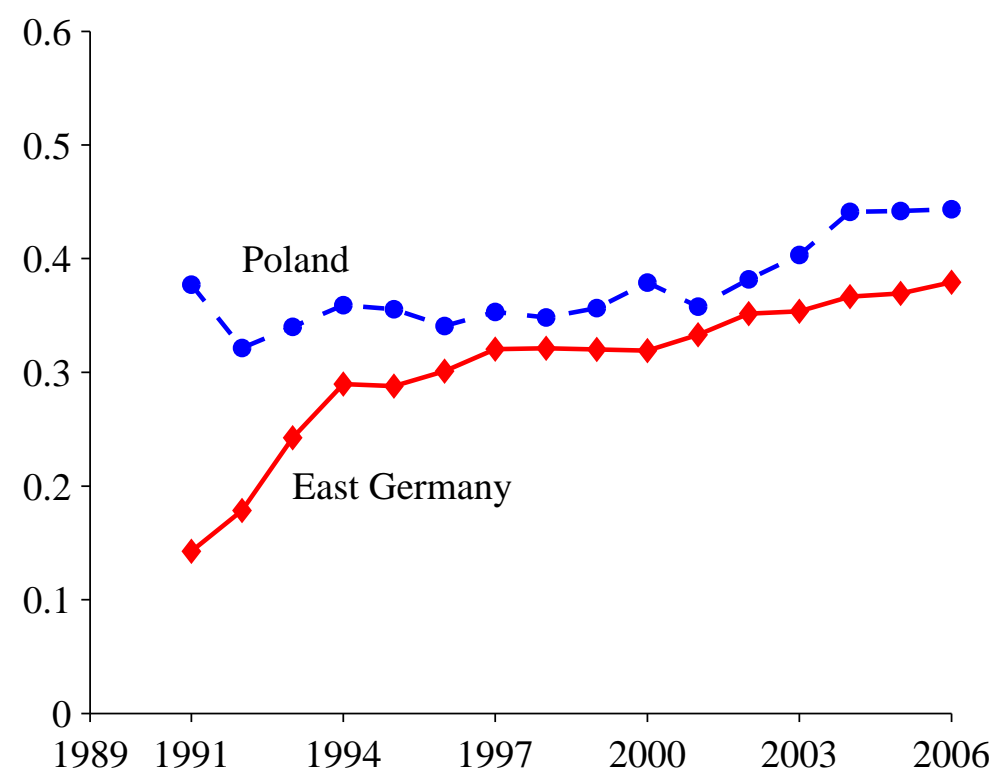


Figure 3: The Capital Share in a Model with Technology Change Only

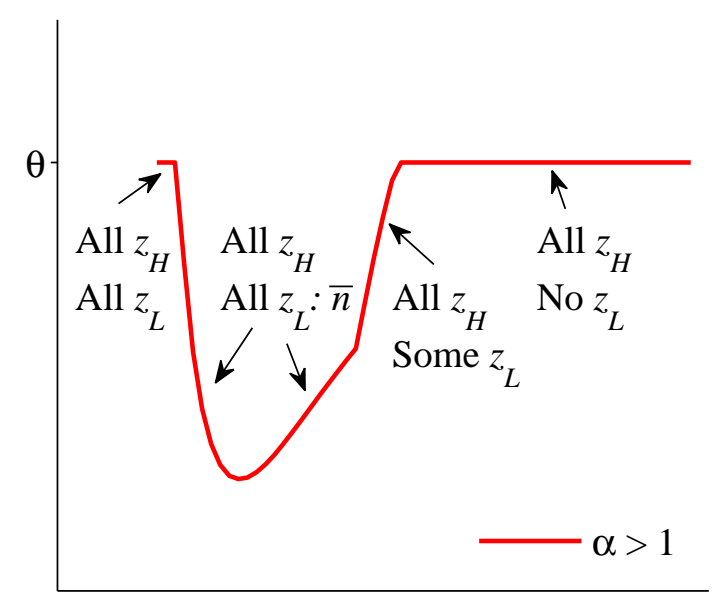

time, $t$

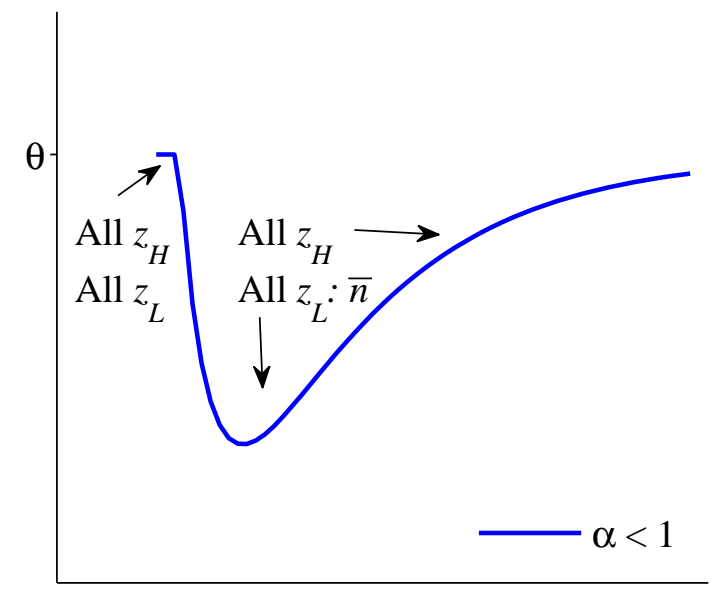

time, $t$

Figure 4: The Capital Share in a Model with Transfers

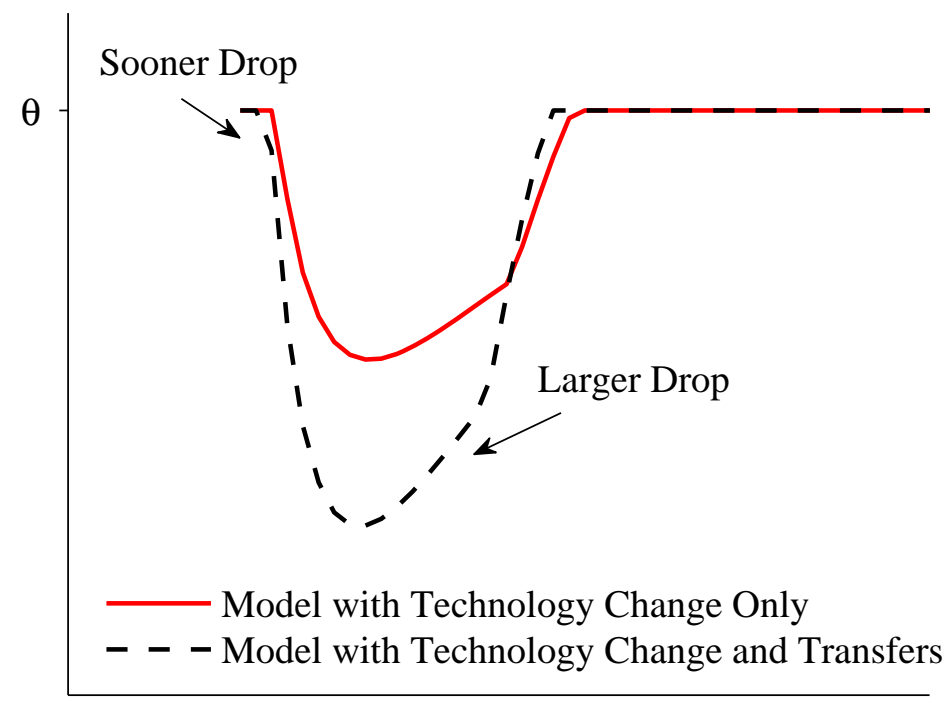


Figure 5: The Capital Share as a Function of Policies

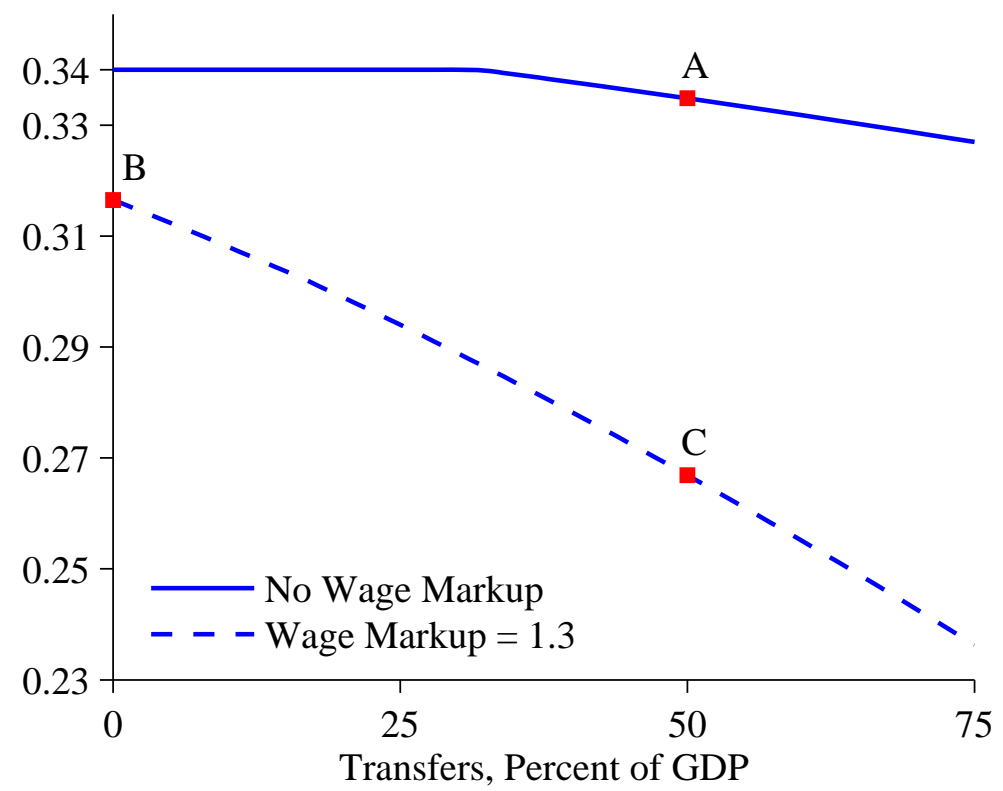

Figure 6: Model Inputs: Transfers and Wage Markups

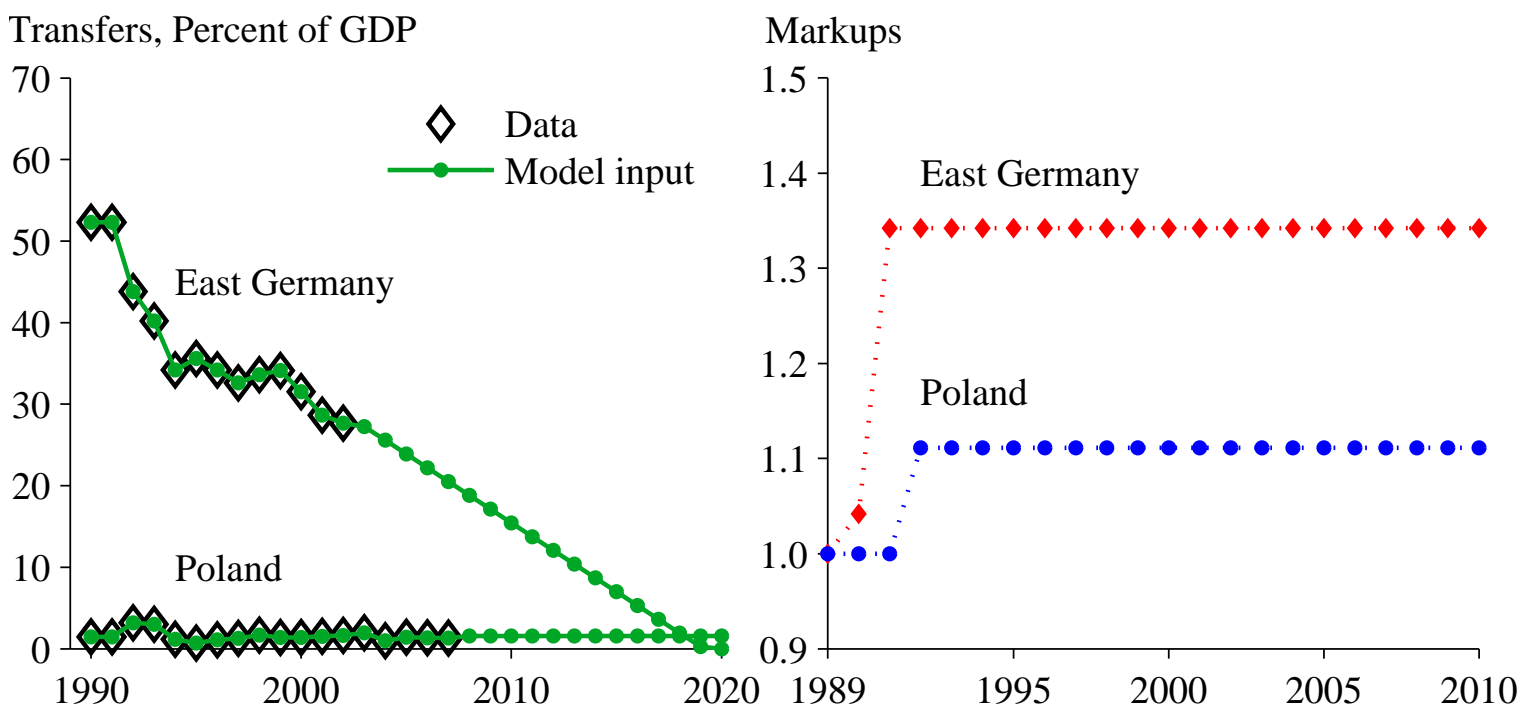


Figure 7: East Germany: Data and Model Predictions
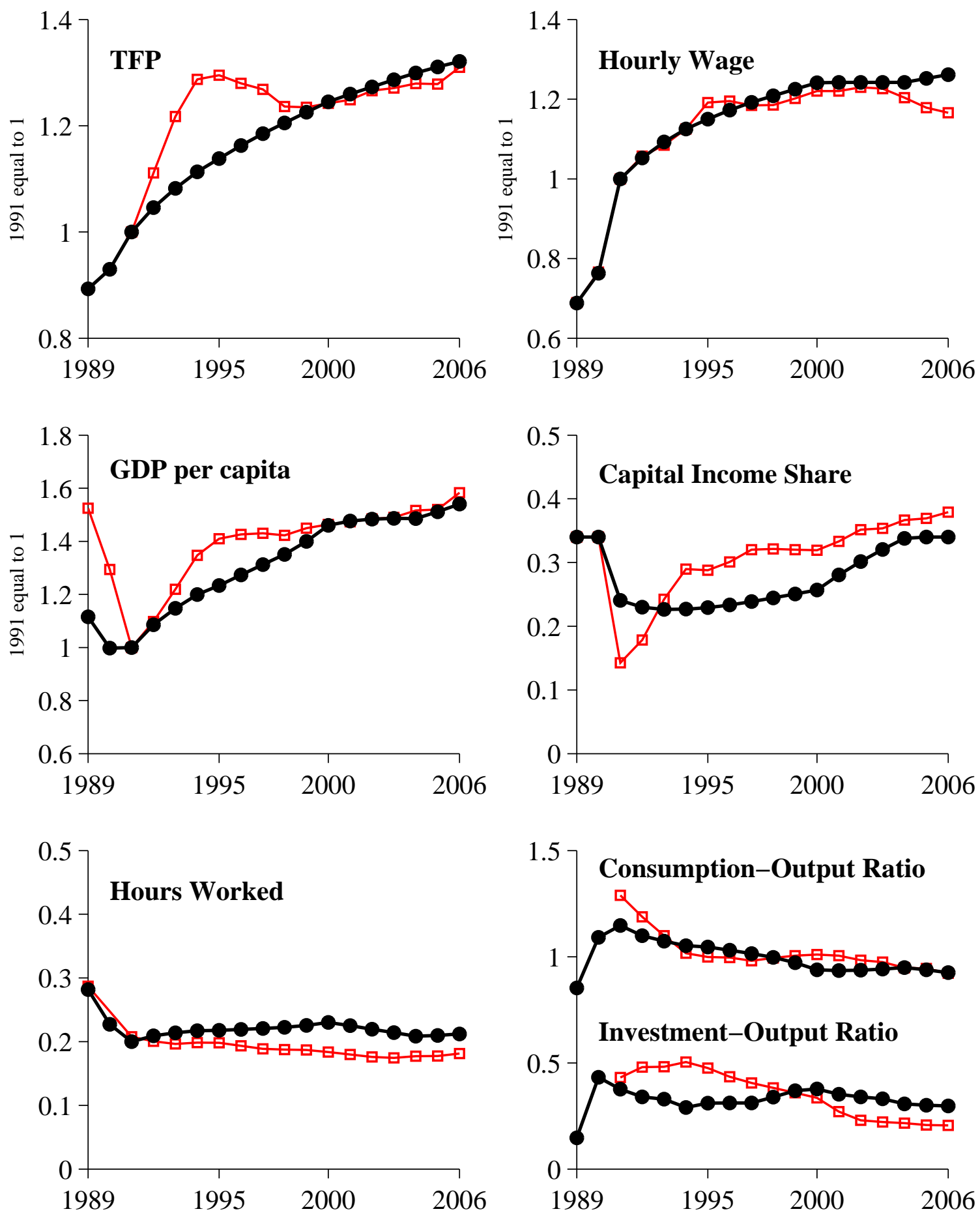

Legend

—-Data, East Germany

$\longrightarrow$ Model with Transfers and Wage Markups 
Figure 8: East Germany: Data and Predictions from Different Experiments
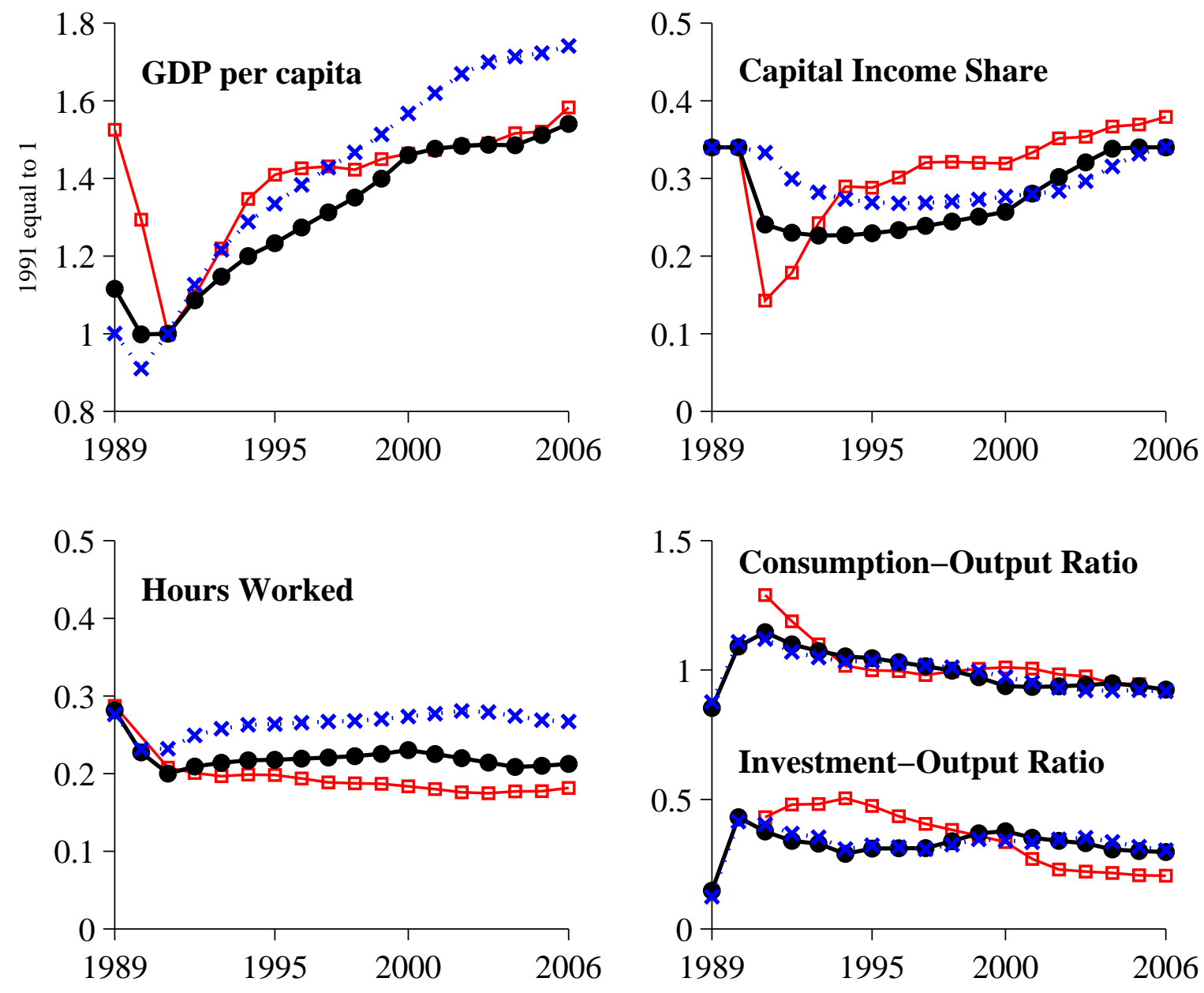

Legend

$\longrightarrow$ Data, East Germany
$\longrightarrow$ - Model with Transfers and Wage Markups
$\cdots \times$. Model with Transfers Only 
Figure 9: Poland: Data and Model Predictions
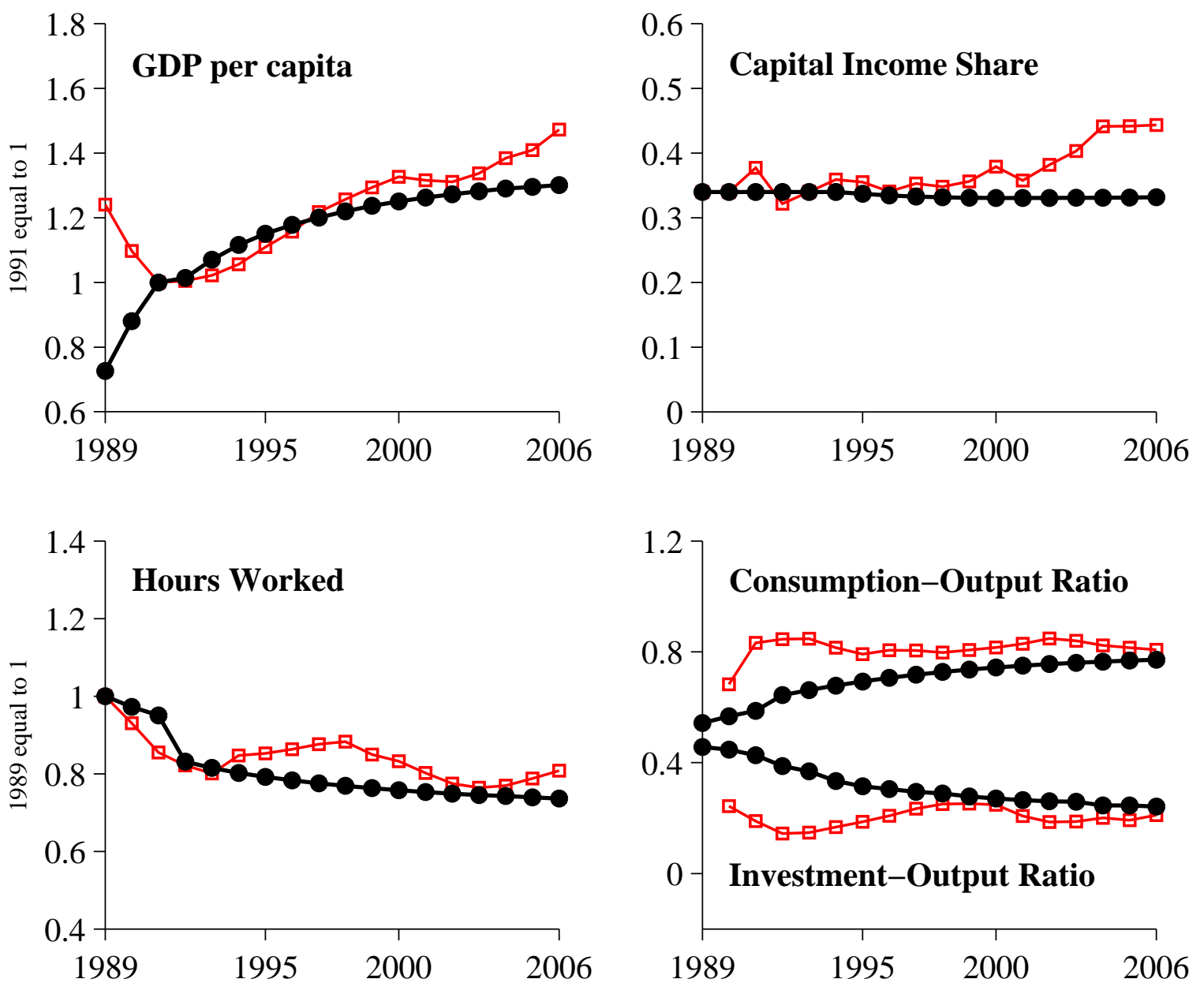

Legend

—— Data, Poland

$\longrightarrow$ Model with Transfers and Wage Markups 